Louisiana State University

LSU Digital Commons

10-1-2009

\title{
Encoding properties of auditory neurons in the brain of a soniferous damselfish: Response to simple tones and complex conspecific signals
}

\author{
Karen P. Maruska \\ Hawai'i Institute of Marine Biology \\ Timothy C. Tricas \\ Hawai'i Institute of Marine Biology
}

Follow this and additional works at: https://digitalcommons.Isu.edu/biosci_pubs

\section{Recommended Citation}

Maruska, K., \& Tricas, T. (2009). Encoding properties of auditory neurons in the brain of a soniferous damselfish: Response to simple tones and complex conspecific signals. Journal of Comparative Physiology A: Neuroethology, Sensory, Neural, and Behavioral Physiology, 195 (11), 1071-1088. https://doi.org/10.1007/s00359-009-0480-1 


\title{
Encoding properties of auditory neurons in the brain of a soniferous damselfish: response to simple tones and complex conspecific signals
}

\author{
Karen P. Maruska $\cdot$ Timothy C. Tricas
}

Received: 20 April 2009/Revised: 10 September 2009/Accepted: 13 September 2009/Published online: 27 September 2009

(C) Springer-Verlag 2009

\begin{abstract}
The fish auditory system encodes important acoustic stimuli used in social communication, but few studies have examined response properties of central auditory neurons to natural signals. We determined the features and responses of single hindbrain and midbrain auditory neurons to tone bursts and playbacks of conspecific sounds in the soniferous damselfish, Abudefduf abdominalis. Most auditory neurons were either silent or had slow irregular resting discharge rates $<20$ spikes $\mathrm{s}^{-1}$. Average best frequency for neurons to tone stimuli was $\sim 130 \mathrm{~Hz}$ but ranged from 80 to $400 \mathrm{~Hz}$ with strong phase-locking. This low-frequency sensitivity matches the frequency band of natural sounds. Auditory neurons were also modulated by playbacks of conspecific sounds with thresholds similar to $100 \mathrm{~Hz}$ tones, but these thresholds were lower than that of tones at other test frequencies. Thresholds of neurons to natural sounds were lower in the midbrain than the hindbrain. This is the first study to compare response properties of auditory neurons to both simple tones and complex stimuli in the brain of a recently derived soniferous perciform that lacks accessory auditory structures. These data demonstrate that the auditory fish brain is most sensitive to the frequency and temporal components of natural pulsed
\end{abstract}

K. P. Maruska · T. C. Tricas

Department of Zoology and Hawai'i Institute of Marine Biology,

University of Hawaii at Manoa, 2538 The Mall,

Honolulu, HI 96822, USA

Present Address:

K. P. Maruska $(\square)$

Biology Department, Stanford University,

371 Serra Mall, Stanford, CA 94305, USA

e-mail: maruska@stanford.edu sounds that provide important signals for conspecific communication.

Keywords Acoustic - Medulla Pomacentridae . Single unit recording . Torus semicircularis

$\begin{array}{ll}\text { Abbreviations } \\ 4 \mathrm{v} & \text { Fourth ventricle } \\ \text { ALLn } & \text { Anterior lateral line nerve } \\ \text { AON } & \text { Anterior octaval nucleus } \\ \text { BDA } & \text { Biotinylated dextran amine } \\ \text { BF } & \text { Best frequency } \\ \text { CC } & \text { Cerebellar crest } \\ \text { CE } & \text { Cerebellum } \\ \text { CV } & \text { Coefficient of variation } \\ \text { DON } & \text { Descending octaval nucleus } \\ \text { EG } & \text { Eminentia granularis } \\ \text { G } & \text { Nucleus glomerulosus } \\ \text { IL } & \text { Inferior lobe of the hypothalamus } \\ \text { MgON } & \text { Magnocellular octaval nucleus } \\ \text { mlf } & \text { Medial longitudinal fasciculus } \\ \text { MON } & \text { Medial octavolateralis nucleus } \\ \text { PLLn } & \text { Posterior lateral line nerve } \\ R & \text { Synchronization coefficient } \\ \text { RF } & \text { Reticular formation } \\ \text { sgt } & \text { Secondary gustatory tract } \\ \text { T } & \text { Tectum } \\ \text { TON } & \text { Tangential octaval nucleus } \\ \text { TS } & \text { Torus semicircularis } \\ \text { VCe } & \text { Valvula cerebelli } \\ \text { Vde } & \text { Descending tract of cranial nerve V } \\ \text { VIIc } & \text { Central tract of cranial nerve VII } \\ \text { VIIm } & \text { Facial motor nucleus } \\ \text { VIIIn } & \text { Cranial nerve VIII } \\ & \end{array}$


VS Vector strength

Z Rayleigh statistic

\section{Introduction}

Sounds detected by the inner ear are important cues used by fishes for predator and prey detection, and social interactions such as courtship and territoriality (see Zelick et al. 1999; Ladich and Myrberg 2006; Myrberg and Lugli 2006). The inner ear of jawed fishes consists of three semicircular canals that serve a vestibular function to encode angular accelerations, and three otolithic endorgans (saccule, lagena, and utricle) that serve gravistasis and auditory functions to encode linear particle motion. Auditory information is transferred from the hair-cell sensory maculae via primary afferents to several hindbrain auditory nuclei, ascends to the midbrain torus semicircularis (TS), and then to forebrain processing regions (see McCormick 1992, 1999 for reviews). While the encoding properties of auditory primary afferents are relatively well-studied in many fishes (see Popper and Fay 1999 for review), less is known about how acoustic signals are encoded in higher processing centers of the fish brain. In addition, previous studies examine encoding properties in species with specialized accessory auditory structures such as the goldfish, catfish, herring and mormyrids (Enger 1967; Page 1970; Fay et al. 1982; Plassmann 1985; Lu and Fay 1993, 1996; Crawford 1993, 1997; Ma and Fay 2002; Suzuki et al. 2002), those that produce high-intensity advertisement 'hums' and 'boatwhistles' such as midshipman and toadfish (Bodnar and Bass 1997, 1999, 2001; Bass et al. 2001; Edds-Walton and Fay 2003, 2005, 2008), or less-derived non-vocal fishes such as the rainbow trout (Schellart 1983; Nederstigt and Schellart 1986; Schellart et al. 1987; Wubbels et al. 1993, 1995; Wubbels and Schellart 1997). However, response properties of single auditory neurons in the brain of more recently derived perciform fishes that produce context-dependent sounds for acoustic communication remain relatively uninvestigated.

The general organization of octavolateralis (auditory, vestibular, mechanosensory) regions of the brain is known in several fishes based on neuroanatomical and neurophysiological studies (McCormick 1992, 1999; Tomchik and Lu 2005; Maruska and Tricas 2009). Primary afferents from the auditory endorgans in fishes project principally to five different nuclei in the hindbrain: anterior, magnocellular, descending, tangential and posterior octaval nuclei. While several studies examine the central projections of auditory nerves and the neuroanatomical connections between the hindbrain and midbrain auditory regions, relatively few neurophysiological studies on encoding properties of the fish hindbrain are available (Page 1970; Sawa 1976; Wubbels et al. 1993; Kozloski and Crawford 2000; Fay and Edds-Walton 2000; Edds-Walton and Fay $1998,2003,2005,2008)$. The TS is the primary midbrain auditory and mechanosensory processing center in fishes and is composed of two main nuclei: nucleus centralis (NC) and nucleus ventrolateralis (NVL). Nucleus centralis is the acoustic processing center and is often located dorsal or medial to the mechanosensory NVL, although the relative positions of these nuclei vary slightly among species (McCormick 1992; O'Marra and McCormick 1999). The TS is analogous to the inferior colliculus of mammals and receives ascending information from the anterior, descending, medial, and superior olivary nuclei in the medulla, and descending information from the diencephalon (Striedter 1991; McCormick 1992; O'Marra and McCormick 1999). While several studies examine the neuroanatomical connections of the TS, relatively few neurophysiological studies on encoding properties of the fish midbrain are available (Nederstigt and Schellart 1986; Lu and Fay 1993, 1996; Crawford 1993, 1997; Bodnar and Bass 1997, 1999, 2001; Bass et al. 2001; Edds-Walton and Fay 2003), and little is known about how complex sounds used for acoustic communication are processed in the fish brain. Thus, comparative studies on response properties of central auditory neurons across taxa are needed to test hypotheses on encoding abilities and sound perception in fishes in order to understand the evolution of acousticdriven sender-receiver physiologies among vertebrates.

Damselfishes (family Pomacentridae) are one of the best studied fish groups for their acoustic behaviors and do not possess special adaptations to enhance detection of the sound pressure component of sound stimuli (see Zelick et al. 1999; Bass and McKibben 2003; Amorim 2006 for reviews). Several genera produce primarily broadband pulsed sounds during territorial and reproductive behaviors, which convey information on species, sex, body size, reproductive readiness, and aggression level (reviewed in Amorim 2006). Previous studies also demonstrate that both the frequency and temporal patterning of the pulsed sounds are critically important for acoustic communication in behaving fish (Myrberg et al. 1993; Lobel and Mann 1995; Myrberg and Lugli 2006). The Hawaiian sergeant fish Abudefduf abdominalis is a colonial benthic spawning damselfish that produces low-frequency, low-intensity pulsed sounds associated with reproductive and agonistic behaviors, and the frequency hearing range matches the spectral components of sounds produced by naturally behaving wild fish (Maruska et al. 2007). The neuroanatomy of the hindbrain octavolateralis system is described for this species as similar to non-vocal perciforms (Maruska and Tricas 2009). However, despite the importance of damselfishes in hearing and acoustic behavior 
research, nothing is published on the encoding properties of auditory signals at the level of single neurons in the brain of any damselfish species.

The purpose of this study was to assess natural signal processing and response properties of auditory neurons within the octaval nuclei of the medulla and the midbrain TS of the Hawaiian sergeant fish. The auditory system was stimulated with both traditional tone bursts as well as playbacks of natural and more complex conspecific signals. Results of this study demonstrate that the auditory fish brain is most sensitive to the frequency and temporal components of natural pulsed sounds that provide important signals for conspecific communication.

\section{Methods}

\section{Experimental animals}

Adult male and female ( $\bar{x}$ standard length $=124.2 \pm$ $7.9 \mathrm{~mm} ; \bar{x}$ body mass $=77.5 \pm 16.3 \mathrm{~g}$ ) Hawaiian sergeant fish, Abudefduf abdominalis, were caught with hook and line from Kane'ohe Bay, Oahu and used immediately in neurophysiology experiments (average time from capture to anesthetization $=10 \mathrm{~min}$ ). At the end of each experiment, fish were measured for standard length and total length to the nearest $0.5 \mathrm{~mm}$, body mass to the nearest $0.1 \mathrm{~g}$, and sex determined by examination of sexually dimorphic genital papillae under a dissection microscope.

\section{Neurophysiology experiments}

Single cell extracellular recordings were made from the auditory region of the TS in the midbrain and the octaval nuclei in the medulla. Fish were anesthetized in a solution of $0.2 \%$ benzocaine and immobilized with an injection of pancuronium bromide ( $\sim 0.001 \mathrm{mg} \mathrm{g}^{-1}$ body mass). Fish were then positioned in an acrylic head holder and fixed in position by stainless steel screws inserted laterally into the cranium behind the eyes. The fish was suspended so that the inner ear was beneath the water surface and $10 \mathrm{~cm}$ above an underwater loudspeaker (UW-30; Lubell Laboratories) partially buried in gravel on the bottom of a $30-\mathrm{cm}$ diameter Nalgene experimental tank (design similar to Fay 1990; McKibben and Bass 1999; Sisneros and Bass 2003). The tank rested on a vibration isolation table (Technical Manufacturing Corporation) inside a sound isolation chamber (Industrial Acoustics). All recording and stimulus generation equipment were located outside of the acoustic booth. Fish were continuously ventilated with seawater (water temperature $23-25^{\circ} \mathrm{C}$; salinity $34-36 \mathrm{ppt}$; without anesthetic) that was pumped from the experimental tank through the mouth and over the gills during all experiments. The brain was exposed by dorsal craniotomy and the cranial cavity filled with Fluorinert fluid (FC-75, $3 \mathrm{M})$ to enhance clarity, reduce bleeding, and prevent drying.

Extracellular single unit discharges were recorded with either glass microelectrodes $(\sim 15-35 \mathrm{M} \Omega)$ filled with $4 \mathrm{M}$ sodium chloride or carbon fiber carbostar-1 electrodes (400-800 k $\Omega$; Kation Scientific, Inc.) that were advanced manually through the tectum down to the TS, or to the octaval nuclei in the medulla. All of the hindbrain neurons and the majority of TS neurons $(>85 \%)$ analyzed in this study were recorded with the low-impedance carbon fiber electrodes, which increased the chances of recording from secondary neurons rather than axons of primary afferents. Initial tracts through the 8th nerve as it enters the medulla confirmed that it was difficult to isolate single primary afferent discharges with these electrodes (strong multi-unit recordings were common). This fact, combined with the recording locations verified by manipulator coordinates and Biotinylated Dextran Amine (BDA) labels (see below), provides support that most hindbrain recordings were not primary afferents.

An auditory search stimulus (100 or $200 \mathrm{~Hz}$ tone bursts at $124-126 \mathrm{~dB}_{\text {rms }}$ re: $1 \mu \mathrm{Pa} ; 10 \mathrm{~ms}$ rise and fall; $20 \mathrm{~ms}$ plateau; $8.3 \mathrm{~Hz}$ repetition rate) was presented to the animal while the electrode was advanced through the brain, and action potentials were monitored visually (oscilloscope) and acoustically (loudspeaker). Only those units that showed a clear response modulation to the underwater speaker stimulus were recorded and classified as auditory units. Units verified as lateral line (response to water movement or touch near canals), somatosensory (response to touch), or other (unknown; no response to any stimulus) were not included in analyses. Neural discharges were amplified $(\times 500-\times 10,000)$ and filtered $(100-5,000 \mathrm{~Hz})$ (Neurolog system, Digitimer Inc.), and then converted to digital files via a Cambridge Electronics Design (CED) power 1401 system and recorded on a computer with associated Spike 2 software.

\section{Stimulus generation}

Acoustic stimuli were generated by the CED digital to analog converter controlled by Spike 2 software, attenuated (CED 3505 programmable attenuator), amplified (Peavey stereo amplifier UMA 352), and played through an underwater loudspeaker (UW-30, Lubbell Labs, frequency response $100 \mathrm{~Hz}-10 \mathrm{kHz}$ ) positioned beneath the fish. Prior to experiments, a calibrated mini-hydrophone (Bruel and Kjaer 8103) was positioned at the location normally occupied by the fish head, and a stimulus routine run to generate a frequency-stimulus amplitude lookup table. This table was then used by the stimulus generation script to produce 
fixed stimulus sound pressure levels across test frequencies $(80-800 \mathrm{~Hz})$. These data were used to construct the isointensity response curves. Stimuli consisted of 100 repetitions of $40 \mathrm{~ms}$ ramped tone bursts $(10 \mathrm{~ms}$ rise and fall; $20 \mathrm{~ms}$ plateau; $8.3 \mathrm{~Hz}$ repetition rate) at frequencies of $80-800 \mathrm{~Hz}$ $(80,100,200,300,400,500,600,800 \mathrm{~Hz})$. The frequency response of the loudspeaker was also verified with the minihydrophone positioned in the tank at the spot normally occupied by the fish inner ear. Relative sound pressure levels (SPL) were calculated for each frequency and intensity by measuring the root mean square (rms) voltage at the position normally occupied by the fish head and converted to SPL in $\mathrm{dB}_{\mathrm{rms}}$ re: $1 \mu \mathrm{Pa}$. Sound pressure levels used during these recordings ranged from 80 to $146 \mathrm{~dB}_{\mathrm{rms}}$ re: $1 \mu \mathrm{Pa}$. This experimental tank setup was similar to that used in other fish auditory physiology studies that demonstrated: (1) the primary axis of particle motion is in the vertical plane, orthogonal to the surface of the underwater speaker (McKibben and Bass 1999), and (2) reflections from the tank walls and water surface do not alter the sound pressure waveform of the acoustic signals (Bodnar and Bass 1997; 1999). Our own hydrophone recordings above the speaker at the position normally occupied by the fish head and body confirmed there were no alterations of the waveform from tank reflections.

While the damselfish is likely primarily sensitive to particle motion, it remains difficult to measure sound levels from underwater speakers in terms of particle displacement, and the relationship between particle motion and pressure in small tanks is complex (Parvulescu 1967). One important feature is that measures of particle motion and pressure have a frequency-dependent proportionality that varies with tank configuration and sound source. However, by placement of the fish close to an isointensity stimulus source, frequency-dependent differences in the relative contributions of particle flow and pressure are minimized. Such measures of responses to sound pressure levels close to the source may be of limited utility for some species far from the source, but do provide reasonable estimates of sensitivity for comparison of species sensitive to particle motion among studies that use similar experimental setups (see also McKibben and Bass 1999; Weeg et al. 2002; Sisneros 2007; Horodysky et al. 2008). Furthermore, in the midshipman fish, another species thought to be primarily sensitive to particle motion, saccular primary afferent recordings showed that the isointensity curves based on pressure are similar in shape to isointensity curves based on particle motion, which provides additional support that constant pressure stimuli do not misrepresent auditory tuning properties in particle motion-sensitive fishes (Weeg et al. 2002; Sisneros 2007).

Playbacks of natural A. abdominalis sounds recorded in the field were also used to test the responses of auditory neurons in the midbrain and medulla. These sounds were recorded with a hydrophone and DAT recorder from naturally behaving fish in the wild. Four different natural sounds were tested: aggressive pulse train $(\sim 800 \mathrm{~ms} 3$ pulse train), courtship-female visit $(\sim 2,000 \mathrm{~ms}$ train), nest preparation $(\sim 1,600 \mathrm{~ms}$ train), and courtship-female visit A pulse train $(\sim 5,000 \mathrm{~ms}$ train) sounds (for details on field recordings and sound characteristics see Maruska et al. 2007). These sounds were generated and presented as described above for the tone bursts except that 50 repetitions were used for aggressive pulse train and nest preparation sounds, and 10 repetitions for the two courtship sounds. Sound pressure levels in $\mathrm{dB}_{\mathrm{rms}}$ re: $1 \mu \mathrm{Pa}$ were determined with a calibrated hydrophone and calculated as described above. Waveforms of these complex stimuli recorded by the hydrophone at the position normally occupied by the fish head and body were spectrally similar to the driver waveform files and showed no significant distortion. Any non-linear sound pressure features were corrected for during calibration with the stimulus generation script as described above for sinusoidal stimuli. Thresholds for these natural sounds were determined as the lowest intensity to show a peri-stimulus time histogram with increased spike rates that were two standard deviations above background correlated in time with the stimulus waveform.

\section{Data analysis}

Data analysis was performed both on- and off-line with Spike 2 software (CED) and values are reported as mean \pm standard deviation. Spontaneous (resting) discharge rates were recorded for each unit in the absence of stimulation, and then used to generate interspike interval (ISI) histograms with $2 \mathrm{~ms}$ bins. A minimum of 500 spikes of resting activity were recorded prior to stimulation, with the exception of silent units. The coefficient of variation (CV), which is a dimensionless ratio of standard deviation to mean interspike interval was also calculated for each unit to estimate relative variability in resting discharge patterns. Units with resting activity were classified as regular (normal distribution; $\mathrm{CV} \leq 0.40$ ) or irregular (Poisson-like distribution; CV $>0.40$ ) based on the shape of their interspike interval histogram and $\mathrm{CV}$ values.

Once resting rate data were recorded, the first stimulus frequency was tested. Thresholds were determined for each test frequency by starting with a suprathreshold intensity followed by decreasing intensities in 5-dB steps until the unit no longer responded to the stimulus. Threshold was defined as the lowest intensity to evoke a significant $Z$ value ( $\geq 4.5$; see below), and best frequency (BF) was defined as the frequency with the lowest threshold. Neuron responses to tone bursts were quantified for vector strength 
(VS) (or synchronization coefficient, $R$ ) across the entire stimulus cycle. VS was calculated according to Goldberg and Brown (1969) and is a measure of the degree of phaselocking to a periodic signal determined by the mean vector length for the circular distribution of spikes over the stimulus period. VS varies from zero (random distribution; no phase-locking) to one (all spikes fall in the same bin; strong phase-locking). The degree of phase-locking was determined to be a better predictor of auditory frequency encoding among vertebrates compared to maximum evoked spike rates for frequencies $\leq 1 \mathrm{kHz}$ (Fay 1978a, 1982, 1994; Javel and Mott 1988; Sisneros and Bass 2003). The significance of phase-locking was determined by calculation of the Rayleigh statistic, $Z$. $Z$ is defined as $R^{2} \times N$, where $N$ is the total number of spikes sampled. The probability of observing $Z \geq 4.5$ by chance is 0.01 (Batschelet 1981 ), thus responses with $Z$ values $\geq 4.5$ were significantly phase-locked (Lu and Fay 1993).

Identification of recording sites

Electrode positions were labeled in several individuals to verify recordings were made within the TS of the midbrain $(N=7)$ and the octaval nuclei of the hindbrain $(N=8)$. Multi-barrel electrodes (carbostar-4; Kation Scientific, Inc.) were filled with Texas Red or Fluorescein BDA neuronal tracers (Vector Laboratories). The electrode was advanced to the auditory TS or medulla and following the single unit recording, the neuronal tracer was pressure ejected ( $\sim 5-20 \times 30 \mathrm{~ms}$ pulses at 20-30 psi; Picospritzer II, General Valve Corp.). At the end of the experiment, the fish was either perfused with $0.9 \%$ heparinized saline followed by $4 \%$ paraformaldehyde in $0.1 \mathrm{M}$ phosphate buffer (PB), or the brain just removed and placed in the fixative. Brains were then postfixed for $24 \mathrm{~h}$, rinsed in $0.1 \mathrm{M} \mathrm{PB}$, cryoprotected in $30 \%$ sucrose in $0.1 \mathrm{M}$ PB overnight, and sectioned in the transverse plane at $24 \mu \mathrm{m}$ on a cryostat. Brain sections were collected onto chrom-alum coated slides, dried at room temperature overnight, and coverslipped with vectashield mounting media (Vector Laboratories) for visualization on a Zeiss Axioskop 2 fluorescent microscope. Monochrome photographs were taken with an Optronics ${ }^{\circledR}$ Macrofire digital camera attached to the fluorescent microscope and some were digitally inverted with Adobe Photoshop software.

\section{Results}

Identification of recording sites

Recording sites in the auditory midbrain $(N=7)$ and hindbrain $(N=8)$ were verified by label with fluorescent- conjugated BDAs (Fig. 1). Midbrain recording sites were all localized to the dorso-lateral TS at $\sim 1.5-2.5 \mathrm{~mm}$ below the surface of the tectum, while hindbrain recording sites were localized primarily to the intermediate region of the descending octaval nucleus (DONi), and a few to the magnocellular octaval nucleus (MgON) (Fig. 1). Not all recording sites were labeled, but correspondence between brain surface landmarks, manipulator coordinates and labeled sites verified that all recordings were likely made within the TS or the octaval nuclei.

Resting discharge activity

\section{Midbrain}

Resting discharge activity was recorded for a total of 109 single auditory neurons in the TS of 33 fish. Two general resting discharge patterns were observed in auditory units of the TS: silent and irregular (Fig. 2a). The mean resting discharge rate for TS auditory units was $13.5 \pm 15.6$ spikes $\mathrm{s}^{-1}$ and ranged from 0 spikes $\mathrm{s}^{-1}$ (or silent) to

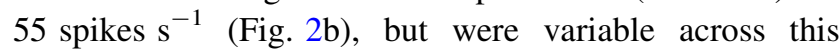
range. The majority of units had resting rates $\leq 20$ spikes s ${ }^{-1}(71 \%)$, while $33 \%$ were silent, and $27 \%$ had resting rates $>20$ spikes $\mathrm{s}^{-1}$. The mean $\mathrm{CV}$ for all spontaneously active units was $0.81 \pm 0.07$, and all were characterized with irregular discharge patterns $(\mathrm{CV}$ values $\geq 0.40)$. There was also a positive relationship between mean interspike interval and $\mathrm{CV}$ for single midbrain units (linear regression; $P=0.04$ ).

\section{Hindbrain}

Resting discharge activity was recorded from a total of 73 single auditory neurons in the medulla of 16 fish. The mean resting discharge rate for hindbrain auditory units was

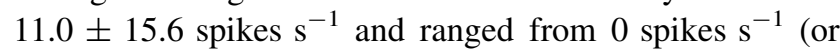
silent) to 74.6 spikes s $^{-1}$ (Fig. 2). The majority of hindbrain units also had resting rates $\leq 20$ spikes s $^{-1}(82 \%)$, while $32 \%$ were silent, and $18 \%$ had resting rates

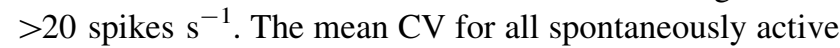
units was $0.98 \pm 0.5$, and all were characterized with irregular discharge patterns ( $\mathrm{CV}$ values $\geq 0.40)$. In contrast to midbrain units, there was no relationship between mean interspike interval and $\mathrm{CV}$ for single hindbrain neurons (linear regression; $P=0.49$ ).

There was no difference in resting discharge rate among non-silent midbrain and hindbrain neurons (Mann-Whitney rank-sum test, $P=0.47$ ), but $\mathrm{CV}$ values were higher in the medulla compared to the TS (Table 1; MannWhitney rank-sum test, $P=0.02$ ). Hindbrain and midbrain neurons had a similar percentage of silent units, but the hindbrain had twice as many units with resting discharges 

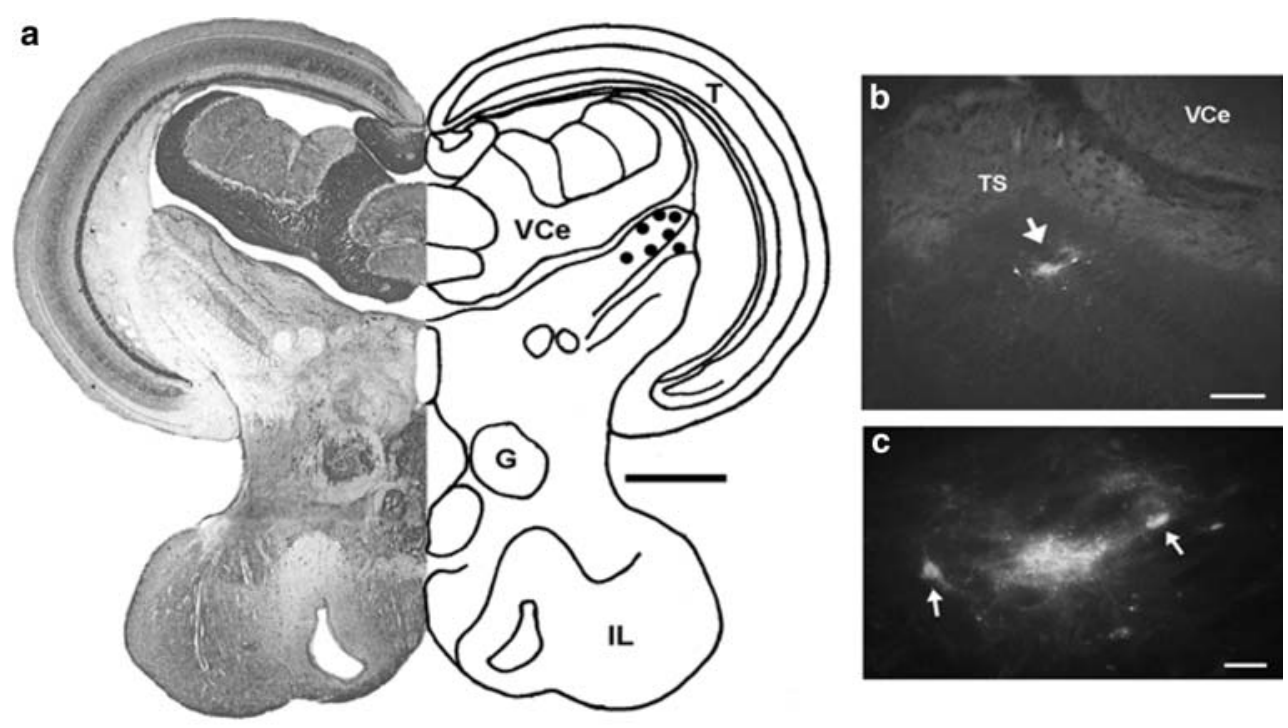

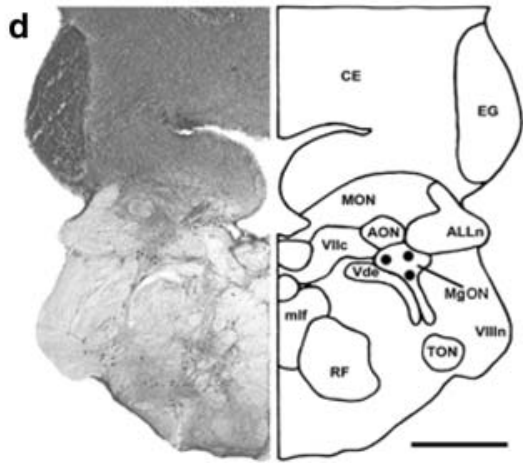

Fig. 1 Verification of recording sites in the auditory torus semicircularis and medulla of the Hawaiian sergeant fish, Abudefduf abdominalis. a Representative transverse section through the brain shows the location of seven labeled recording sites (dots) within the dorso-lateral torus semicircularis of the midbrain, superimposed on a single section. b FITC-BDA label of a single recording site (arrow) in the torus semicircularis (TS). c Higher magnification of the single recording site shown in b. Arrows indicate labeled torus cell bodies in the vicinity of the recording site. $\mathbf{d}$ Representative transverse section

from 1 to 15 spikes $\mathrm{s}^{-1}$ compared to the more variable resting rates of the TS (see Fig. 2b).

Response to tone bursts: frequency response, phase-locking, threshold, and level encoding

Auditory neurons in the midbrain TS and medulla of the Hawaiian sergeant fish responded with an increase in spike rate and some degree of phase-locking to tone stimuli from 80 to $800 \mathrm{~Hz}$. Auditory neurons in the midbrain showed phasic responses with more action potentials during the start of the stimulus burst (e.g., cycles 1-3) compared to later cycles, and a small percentage of units (25\%) also responded to the offset of the stimulus (Fig. 3). This same response to the offset of the stimulus burst was not observed in any neurons of the auditory medulla. e

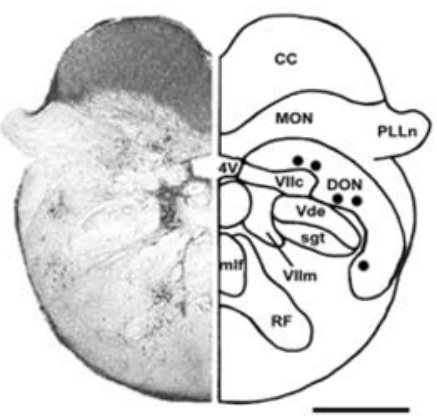

through the rostral medulla shows the location of several labeled recording sites within the magnocellular octaval nucleus $(\mathrm{MgON})$ superimposed on a single section. e Representative transverse section through the caudal medulla shows several labeled recording sites in the descending octaval nucleus $(D O N)$ superimposed on a single section. For a, d, and e, left side is stained with cresyl violet and right is the inverted camera lucida drawing. See list for other abbreviations. Scale bars $1 \mathrm{~mm}(\mathbf{a}, \mathbf{d}, \mathbf{e}), 100 \mu \mathrm{m}$ (b) $5 \mu \mathrm{m}$ (c)

\section{Midbrain}

BFs for auditory neurons in the TS ranged from 80 to $300 \mathrm{~Hz}$ (Fig. 4). Mean BF was $126.7 \pm 55.5 \mathrm{~Hz}$ and the majority of neurons $(60 \%)$ had a $\mathrm{BF}$ at $100 \mathrm{~Hz}$, while 16 and $23 \%$ had BFs of 80 and $200 \mathrm{~Hz}$, respectively. There were no neurons with BFs above $300 \mathrm{~Hz}$ in the auditory TS (Fig. 4).

Threshold tuning curves were determined for a total of 88 auditory neurons in the TS of 28 fish (Figs. 5, 6). Thresholds to tone burst stimuli ranged from $104.2 \pm$ $9.3 \mathrm{~dB}_{\text {rms }}$ re: $1 \mu \mathrm{Pa}$ at $100 \mathrm{~Hz}$ to $141.8 \pm 5.5 \mathrm{~dB}_{\text {rms }}$ re: $1 \mu \mathrm{Pa}$ at $800 \mathrm{~Hz}$ (Fig. 5). Thus, there was an average dynamic range of $35-40 \mathrm{~dB}$ between mean thresholds at the $\mathrm{BF}(100 \mathrm{~Hz})$ and maximum frequency $(800 \mathrm{~Hz})$. Most neurons in the TS were sharply tuned to low frequencies 
Fig. 2 Resting discharge activity of auditory neurons in the midbrain torus semicircularis and medulla. a Interspike interval (ISI) histograms of resting discharge activities for individual auditory neurons. Histograms were calculated from 500 spikes in the absence of stimulation and compiled into 2-ms bins.

Examples of slow $\left(<5\right.$ spikes s $\left.^{-1}\right)$ (top row) and fast $\left(>20\right.$ spikes s $^{-1}$ ) (bottom row) irregular units are shown for both the midbrain TS and medulla. Insets show 1-s recordings of neural activity for each unit. b Resting discharge activity for populations of single auditory neurons. $N$ number of animals, number of units
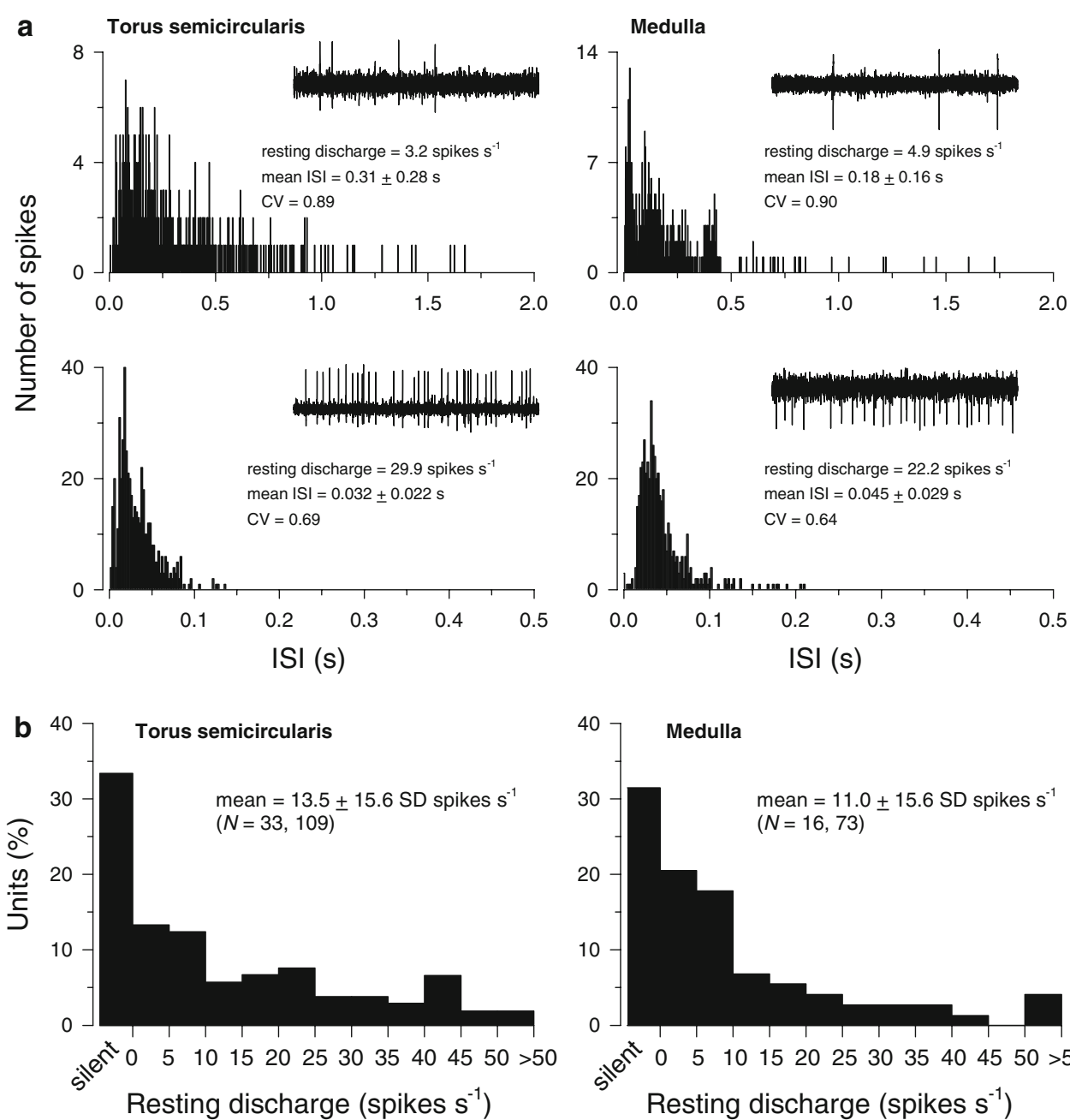

with steep fall offs at higher frequencies (29.5 \pm $3.3 \mathrm{~dB}$ octave $^{-1}$ from $400-800 \mathrm{~Hz}$ ), but there were also some units that showed broader tuning $(12.2 \pm 4.5 \mathrm{~dB}$ octave $^{-1}$ from 400 to $800 \mathrm{~Hz}$; Fig. 5). Further, some units did not respond to frequencies above $300-400 \mathrm{~Hz}$, even at the highest intensity levels tested. Threshold tuning curves for five individual neurons are plotted in Fig. 5a to illustrate the variability in threshold levels, tuning curve shape, and BF among units. Thresholds of individual auditory neurons were also variable, with a minimum threshold of $86 \mathrm{~dB}_{\mathrm{rms}}$ re: $1 \mu \mathrm{Pa}$ detected at $100 \mathrm{~Hz}$. The greatest difference between minimum and maximum threshold was at $200 \mathrm{~Hz}(54 \mathrm{~dB})$, and the smallest differences were at $800 \mathrm{~Hz}(20 \mathrm{~dB})$ and $100 \mathrm{~Hz}(23 \mathrm{~dB})$. These low-frequency response properties of the auditory system are also matched to the frequency components of the natural conspecific sounds produced by this species (Fig. 6a). The greatest energy of all conspecific sounds is from $<80$ to $400 \mathrm{~Hz}$, which corresponds to the best frequency sensitivity of auditory neurons in both the midbrain and hindbrain $(80-400 \mathrm{~Hz})$.
In the Hawaiian sergeant fish, all of the auditory neurons in the TS showed significant phase-locking at threshold and suprathreshold levels (Fig. 7a). When calculated at $5 \mathrm{~dB}$ above threshold at each units' BF, 44 and $56 \%$ of units showed weak $(\mathrm{VS}<0.5)$ and strong $(\mathrm{VS} \geq 0.5)$ phaselocking, respectively. In contrast, when calculated at a near isointensity level $(119-124 \mathrm{~dB})$ at the same frequency $(100 \mathrm{~Hz})$, there were fewer weak $(24 \%)$ and more strong (76\%) phase-locked neurons (Fig. 7a). Vector strength and Rayleigh statistic values were both higher at the suprathreshold values calculated at $100 \mathrm{~Hz}(\bar{x}$ VS $=0.63 \pm$ $0.18 ; \bar{x} Z=72.1 \pm 53.1)$ compared to those determined at $5 \mathrm{~dB}$ above threshold at the units' $\mathrm{BF}(\bar{x} \mathrm{VS}=0.55 \pm$ $0.23 ; \bar{x} Z=19.6 \pm 16.1$ ) (Mann-Whitney rank-sum tests, $P=0.02$ for VS; $P<0.001$ for $Z$ ). Examples of period histograms from individual neurons with weak and strong phase-locking abilities are shown in Fig. 5b. Phase-locking ability rather than evoked spike rate is thought to be a better predictor of frequency encoding in the fish auditory system, especially at frequencies $\leq 1 \mathrm{kHz}$ (Fay 1978a, b, 1982, 1994; McKibben and Bass 1999; Sisneros and Bass 
Table 1 Resting discharge and response properties of single auditory neurons in the midbrain torus semicircularis and medulla of the Hawaiian sergeant fish Abudefduf abdominalis
Hindbrain units were recorded from the descending octaval and magnocellular octaval nuclei.

Data are expressed as

mean \pm standard deviation (top line), $25 \%$, median, and $75 \%$ values (middle line), and range (in parentheses on bottom line). Thresholds are in $\mathrm{dB}_{\mathrm{rms}}$ re: $1 \mu \mathrm{Pa}$. Differences between the midbrain torus semicircularis and medulla were tested with the Mann-Whitney rank-sum test and bold numbers with asterisks indicate $P<0.05$

\begin{tabular}{|c|c|c|c|}
\hline & Torus semicircularis & Medulla & $P$ \\
\hline Resting discharge (spikes $\mathrm{s}^{-1}$ ) & $\begin{array}{l}13.5 \pm 15.6 \\
0,6.2,23.1 \\
(0-55)\end{array}$ & $\begin{array}{l}11.0 \pm 15.6 \\
0,4.8,14.7 \\
(0-75)\end{array}$ & 0.47 \\
\hline Coefficient of variation $(\mathrm{CV})$ & $\begin{array}{l}0.81 \pm 0.07 \\
0.67,0.77,0.91 \\
(0.41-1.6)\end{array}$ & $\begin{array}{l}0.98 \pm 0.5 \\
0.74,0.90,1.2 \\
(0.41-1.7)\end{array}$ & $0.02 *$ \\
\hline Best frequency $(\mathrm{Hz})$ & $\begin{array}{l}126.7 \pm 55.5 \\
100,100,200 \\
(80-300)\end{array}$ & $\begin{array}{l}134.8 \pm 75.9 \\
100,100,200 \\
(80-400)\end{array}$ & 0.86 \\
\hline Vector strength at BF & $\begin{array}{l}0.55 \pm 0.23 \\
0.34,0.53,0.75 \\
(0.18-0.96)\end{array}$ & $\begin{array}{l}0.59 \pm 0.21 \\
0.46,0.62,0.74 \\
(0.12-0.96)\end{array}$ & 0.20 \\
\hline \multicolumn{4}{|l|}{ Threshold to } \\
\hline $100 \mathrm{~Hz}$ tone burst & $\begin{array}{l}104.2 \pm 9.3 \\
97,101,111 \\
(86-129)\end{array}$ & $\begin{array}{l}105.5 \pm 12.5 \\
96,106,116 \\
(81-136)\end{array}$ & 0.37 \\
\hline Courtship-female visit sound & $\begin{array}{l}105.7 \pm 3.5 \\
104,105,107 \\
(103-120)\end{array}$ & $\begin{array}{l}109.6 \pm 5.6 \\
104,109,115 \\
(103-120)\end{array}$ & $0.009 *$ \\
\hline Courtship A pulses sound & $\begin{array}{l}104.5 \pm 2.8 \\
103,104,105 \\
(102-117)\end{array}$ & $\begin{array}{l}106.9 \pm 3.9 \\
104,105,109 \\
(102-117)\end{array}$ & $0.002 *$ \\
\hline Aggressive pulse train sound & $\begin{array}{l}103.5 \pm 2.5 \\
102,103,103 \\
(100-114)\end{array}$ & $\begin{array}{l}104.7 \pm 3.0 \\
103,104,106 \\
(102-114)\end{array}$ & $0.04 *$ \\
\hline Nest preparation sound & $\begin{array}{l}105.0 \pm 3.6 \\
103,103,106 \\
(103-119)\end{array}$ & $\begin{array}{l}106.2 \pm 3.6 \\
103,105,110 \\
(103-114)\end{array}$ & 0.06 \\
\hline
\end{tabular}

2003). Examples of average evoked spike rates and vector strength values for two individual neurons calculated at near isointensity levels $(130 \pm 5 \mathrm{~dB}$ re: $1 \mu \mathrm{Pa})$ show the differences in these parameters (Fig. 5c). The neuron in the top left panel of Fig. 5c had a resting discharge of

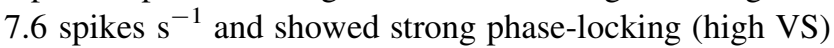
from 80 to $200 \mathrm{~Hz}$, but elevated evoked spike rates from 80 to $500 \mathrm{~Hz}$. The neuron in the lower left panel was silent and showed strong phase-locking (VS $>0.80)$ and elevated spike rates from 80 to $300 \mathrm{~Hz}$. However, notice the highest VS value occurs at the lowest evoked spike rate for this neuron at $300 \mathrm{~Hz}$. This unit also showed no response to frequencies from 400 to $800 \mathrm{~Hz}$ at this intensity level. These data highlight the variability and complexity of response properties in both the midbrain and hindbrain and that individual neurons may use either spike rate or VS to encode frequency information depending on sound frequency and intensity.

Vector strength at BF for midbrain TS neurons also showed an inverse relationship with resting discharge rate (linear regression, $P<0.001$ ) (Fig. 7b). Vector strength values for silent units ranged from 0.20 to 0.97 , but silent units and those with slow resting discharges had higher average vector strength values than those with higher resting discharges.

Response-level curves for auditory neurons in the TS in response to tone bursts at the $\mathrm{BF}$ of $100 \mathrm{~Hz}$ are shown in Fig. 8. Rate-intensity curves show that as sound level is increased, discharge rate increases as a near monotonic function of stimulus intensity, but individual neurons can vary in dynamic range and slope. In comparison, the synchronization-intensity curves show that vector strength also increases with increased sound intensity, but often reaches a plateau at higher intensities while spike rate continues to increase (Fig. 8).

\section{Hindbrain}

BFs for auditory neurons in the hindbrain ranged from 80 to $400 \mathrm{~Hz}$ (Fig. 4). Mean BF for hindbrain neurons was $134.8 \pm 75.9 \mathrm{~Hz}$, and the majority of neurons (49\%) had a $\mathrm{BF}$ at $100 \mathrm{~Hz}$, while 22 and $23 \%$ had BFs of 80 and 

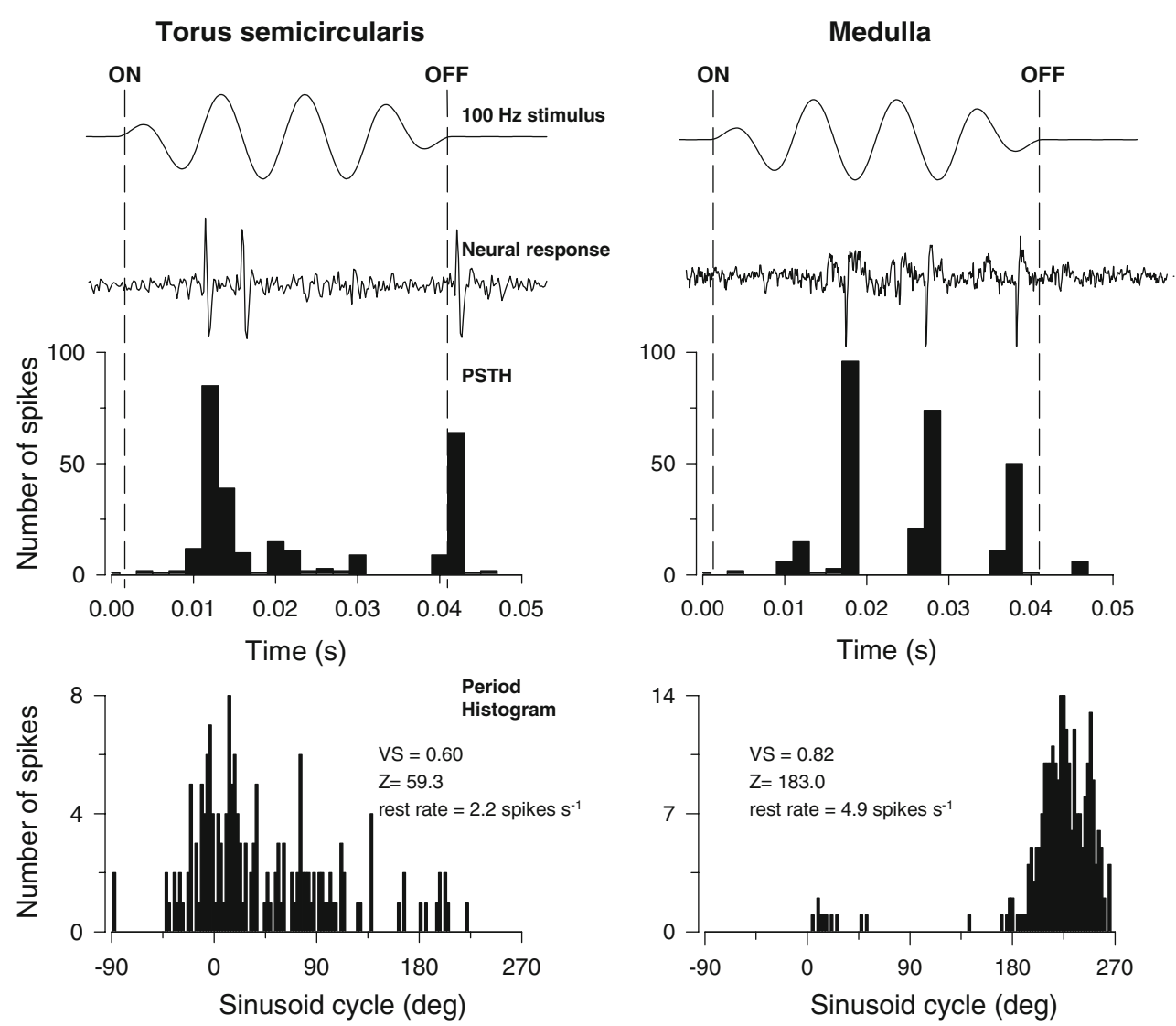

Fig. 3 Responses of representative single auditory neurons to a $100 \mathrm{~Hz}$ tone burst. Top two traces show a single 100-Hz stimulus tone burst and resultant neural response. The peri-stimulus time histogram (PSTH) shows the neural responses binned over 100 successive stimulus presentations. Note the strong phase-locking and offset

response to the stimulus in the TS unit. Bottom graphs show the period histograms of each unit relative to single sinusoid cycles. $O N$ and $O F F$ indicate the onset and offset of the 40-ms stimulus. $V S$ vector strength, $Z$ Rayleigh statistic

$200 \mathrm{~Hz}$, respectively. No neurons with BFs above $400 \mathrm{~Hz}$ were identified in the auditory hindbrain (Fig. 4).

Threshold tuning curves were determined for a total of 69 auditory neurons in the medulla of 16 fish (Figs. 5, 6). Thresholds ranged from $105.3 \pm 12.5 \mathrm{~dB}_{\text {rms }}$ re: $1 \mu \mathrm{Pa}$ at $100 \mathrm{~Hz}$ to $141.5 \pm 8.5 \mathrm{~dB}_{\mathrm{rms}}$ re: $1 \mu \mathrm{Pa}$ at $800 \mathrm{~Hz}$ (Fig. 5a). Thus, there was an average dynamic range of $35 \mathrm{~dB}$ between mean thresholds at the best $(100 \mathrm{~Hz})$ and worst frequency $(800 \mathrm{~Hz})$. Many neurons in the hindbrain were more broadly tuned compared to those in the midbrain with a mean fall-off of $21.5 \pm 6.4 \mathrm{~dB}$ octave $^{-1}$ from 400 to $800 \mathrm{~Hz}$, but there were also some neurons with sharp tuning similar to midbrain units. Threshold tuning curves for several individual neurons are plotted in Fig. 5a to illustrate the variability in threshold levels, tuning curve shape, and BF among medullary units. Thresholds of individual hindbrain neurons were also variable, with a minimum threshold of $81 \mathrm{~dB}_{\text {rms }}$ re: $1 \mu \mathrm{Pa}$ detected at $100 \mathrm{~Hz}$. The greatest difference between minimum and maximum threshold was at $300 \mathrm{~Hz}(58 \mathrm{~dB})$, and the smallest difference was at $800 \mathrm{~Hz}(33 \mathrm{~dB})$.

Similar to the midbrain, all hindbrain auditory units showed significant phase-locking at threshold and suprathreshold levels (Fig. 7a). At $5 \mathrm{~dB}$ above threshold at BF, phase-locking was weak for $28 \%$ of units (VS $<0.5$ ) and strong for $72 \%$ (VS $\geq 0.5$ ). When calculated at a near isointensity level (119-124 dB) at $100 \mathrm{~Hz}$, the proportions of weak $(26 \%)$ and strong (74\%) phase-locked neurons were maintained. Rayleigh statistic values, but not vector strength, were higher at the suprathreshold values calculated at $100 \mathrm{~Hz}(\bar{x} \mathrm{VS}=0.65 \pm 0.20 ; \bar{x} Z=98.6 \pm 80.3)$ compared to those determined at $5 \mathrm{~dB}$ above threshold at $\mathrm{BF}(\bar{x} \mathrm{VS}=0.59 \pm 0.21 ; \bar{x} \quad Z=26.9 \pm 25.8)$ (MannWhitney rank-sum tests, $P=0.14$ for VS; $P<0.001$ for $Z$ ) (Fig. 7a). Examples of period histograms from individual hindbrain neurons with weak and strong phaselocking abilities are shown in Fig. 5b. Average evoked spike rates and vector strength values calculated at near isointensity levels ( $130 \pm 5 \mathrm{~dB}$ re: $1 \mu \mathrm{Pa})$ for two representative hindbrain units show differences in these features (Fig. 5c). The neuron in the top right panel of Fig. $5 c$ had a resting discharge of 2.8 spikes s ${ }^{-1}$, weak 

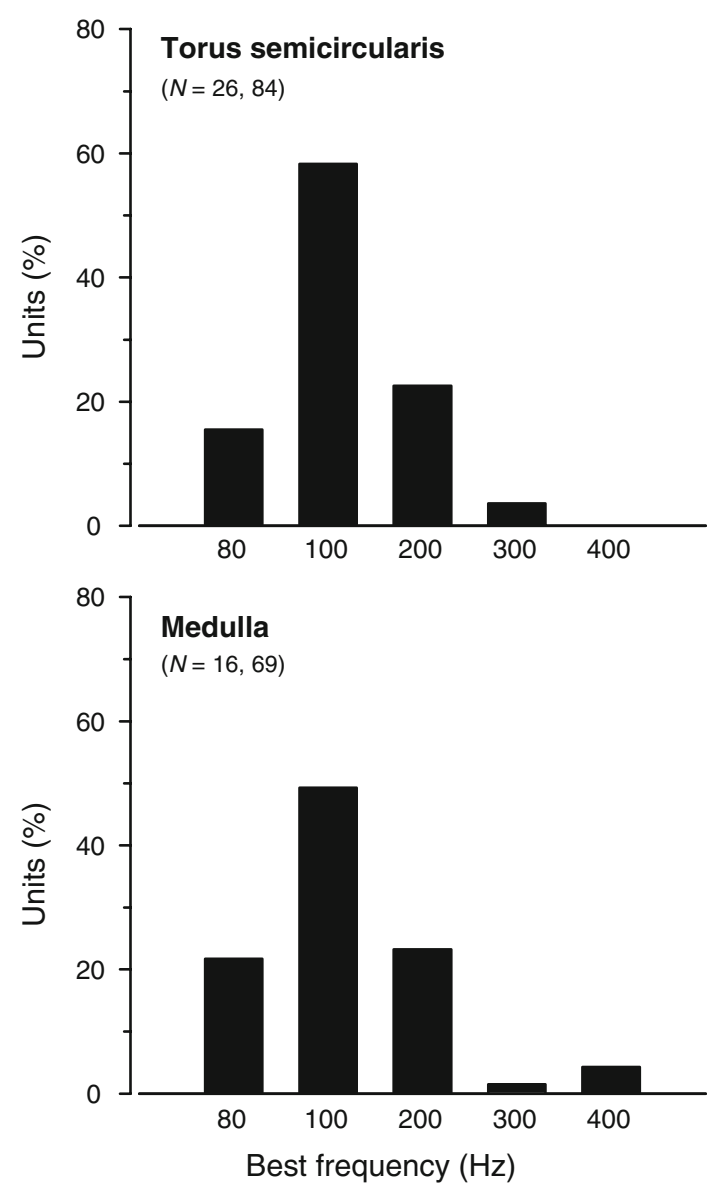

Fig. 4 Best frequency histograms for auditory neurons. The majority of neurons in both the TS and medulla had a BF of $100 \mathrm{~Hz}$. BF was defined as the frequency with the lowest threshold value for each unit. $N$ number of animals, number of units

VS $(<0.50)$, strong phase-locking $(Z \geq 4.5)$ and elevated spike rates from 80 to $500 \mathrm{~Hz}$. In contrast, the neuron in the lower right panel was silent but also showed very strong phase-locking (VS >0.90) from 80 to $400 \mathrm{~Hz}$ and a clear peak in spike rate at $200 \mathrm{~Hz}$. This unit also showed no response to frequencies from 500 to $800 \mathrm{~Hz}$ at this intensity level.

Similar to the midbrain, there was also a negative relationship between vector strength at $\mathrm{BF}$ and resting discharge rate for hindbrain auditory neurons (linear regression, $P<0.001$ ) (Fig. 7b). Vector strength values for silent units ranged from 0.12 to 0.96 , but silent units and those with slow resting discharges had higher average vector strength values than those with higher resting discharges. There was no difference in BF, vector strength at $\mathrm{BF}$, or threshold at $100 \mathrm{~Hz}$ between midbrain and hindbrain auditory neurons (Table 1; Mann-Whitney rank-sum tests, $P>0.05$ ).

Response-level curves for auditory neurons in the medulla in response to tone bursts at the $\mathrm{BF}$ of $100 \mathrm{~Hz}$ are shown in Fig. 8. Rate-intensity curves show the variability in response patterns among units. Spike rates of some units increase as a monotonic function of stimulus intensity. However, other neurons show little or no change in spike rate as sound level increased. Further, the synchronizationintensity curves show that vector strength increases with sound intensity in some neurons, but also shows nonmonotonic functions in others. Thus, spontaneous activity can be redistributed in time to increase phase-locking without a change in spike rate. Vector strength values also decreased at higher intensities in some units due to multiple discharges per stimulus cycle, especially at low frequencies (e.g., 80-100 Hz) (Fig. 8).

Response to complex conspecific sounds

Response properties of single auditory neurons in both the midbrain TS and medulla of the Hawaiian sergeant fish also match the frequency components of natural sounds produced by this species in the wild (Fig. 6). Power spectra of the four natural conspecific sounds used as playback stimuli in this study show peak energy components at low frequencies from $<80$ to $400 \mathrm{~Hz}$, and decreased energy (10-30 dB lower) from 500 to $1,000 \mathrm{~Hz}$. Thus, central auditory neurons are well-suited to detect the low-frequency spectral components of natural sounds.

\section{Midbrain}

Auditory neurons in the TS modulated well to playbacks of pulsed natural complex sounds (Fig. 9). In all cases, individual pulses from each sound type were temporally represented at the single neuron level in the auditory TS. Mean thresholds to playbacks of natural sound waveforms ranged from $103.5 \pm 2.4 \mathrm{~dB}_{\text {rms }}$ re: $1 \mu \mathrm{Pa}$ for the aggressive pulse train sound to $105.7 \pm 3.5 \mathrm{~dB}_{\mathrm{rms}}$ re: $1 \mu \mathrm{Pa}$ for the courtship-female visit sound (Fig. 6c). Thresholds to natural sound stimuli are all within $\pm 2 \mathrm{~dB}$ of the mean threshold at $100 \mathrm{~Hz}$ for the tone bursts (see Fig. 6). However, thresholds for all four natural sounds were lower than thresholds determined for tone bursts at all other frequencies $(80,200-800 \mathrm{~Hz})$ (Kruskal-Wallis oneway ANOVA on ranks, $P<0.001$; Dunn's method, $P \leq 0.05$ ). Auditory neurons in the midbrain also had lower thresholds (1-4 dB lower) to the complex conspecific sounds compared to the hindbrain neurons (Table 1; Fig. 6d).

\section{Hindbrain}

Similar to the midbrain, individual pulses from each sound type were temporally represented at the single 

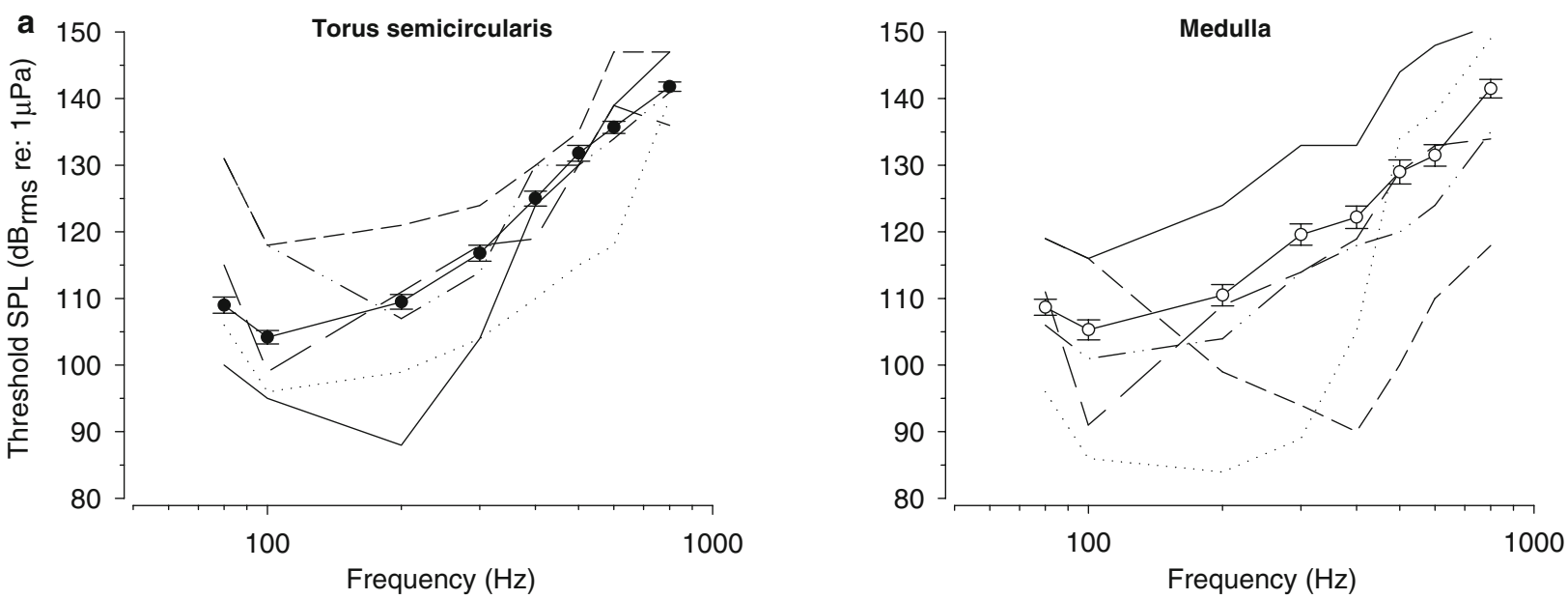

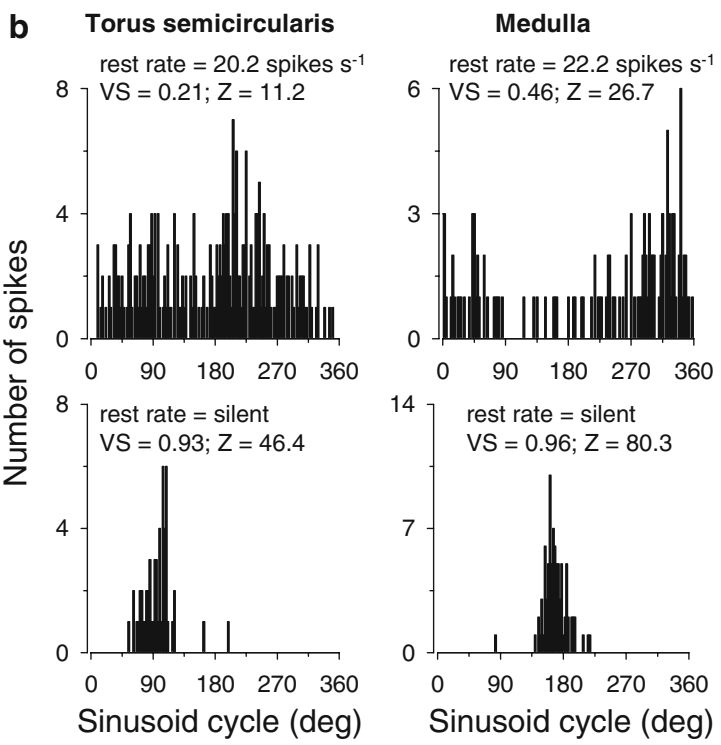

Fig. 5 Frequency response properties of single auditory neurons to tone bursts. a Tuning curves for five individual auditory neurons in both the torus semicircularis (TS) and medulla illustrates the variability in $\mathrm{BF}$, threshold levels, and tuning curve shape among individual neurons. Mean \pm SE are also plotted as closed circles (TS) and open circles (medulla) on each graph. b Period histograms show weak phase-locking for a spontaneously active unit (top row) and

neuron level in the auditory medulla (Fig. 10). Mean thresholds to playbacks of natural sound waveforms ranged from $104.7 \pm 3.0 \mathrm{~dB}_{\text {rms }}$ re: $1 \mu \mathrm{Pa}$ for the aggressive pulse train sound to $109.6 \pm 5.6 \mathrm{~dB}_{\text {rms }}$ re: $1 \mu \mathrm{Pa}$ for the courtship-female visit sound (Fig. 6c). Thresholds to natural sound stimuli are all within $\pm 2 \mathrm{~dB}$ of the mean threshold at $100 \mathrm{~Hz}$ for the tone bursts, and similar to the TS, thresholds for all four natural sounds were lower than thresholds determined for tone bursts at all other frequencies $(80,200-800 \mathrm{~Hz})$ (Kruskal-Wallis one-way ANOVA on ranks, $P<0.001$; Dunn's method, $P \leq 0.05$ ) (see Fig. 6).

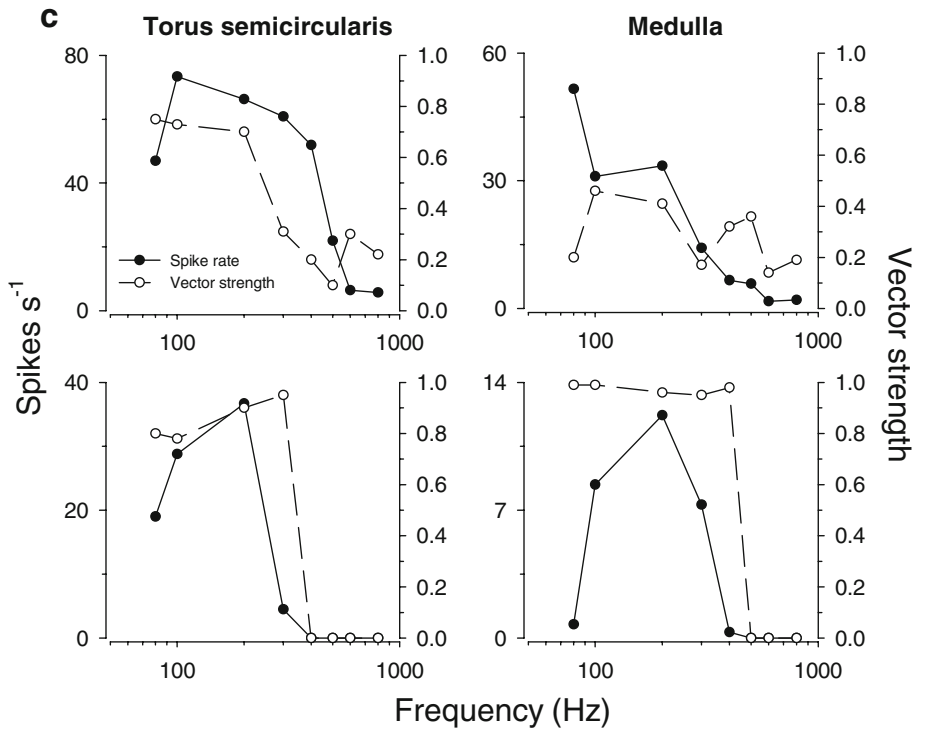

strong phase-locking for a silent unit (bottom row) in both the TS and medulla. c Representative examples of near isointensity (130 $\pm 5 \mathrm{~dB}$ re: $1 \mu \mathrm{Pa}$ ) curves for individual neurons plotted for both average evoked spike rate (closed circles, solid lines) and vector strength (open circles, dashed lines). Resting discharge was 7.6 spikes s ${ }^{-1}$ (top) and silent (bottom) for torus units, and 2.8 spikes s $^{-1}$ (top) and silent (bottom) for medullary units

\section{Discussion}

This is the first study to compare response properties of auditory neurons to both simple tone and complex conspecific stimuli in both the hindbrain and midbrain TS of a perciform soniferous fish that lacks accessory hearing structures. Hindbrain and midbrain auditory neurons in the Hawaiian sergeant fish had slow resting discharge rates, high phase-locking ability, and were most sensitive to low-frequency tone stimuli from 80 to $400 \mathrm{~Hz}$. In addition, central auditory neurons were modulated by playbacks of complex natural conspecific sounds with mean thresholds similar to 


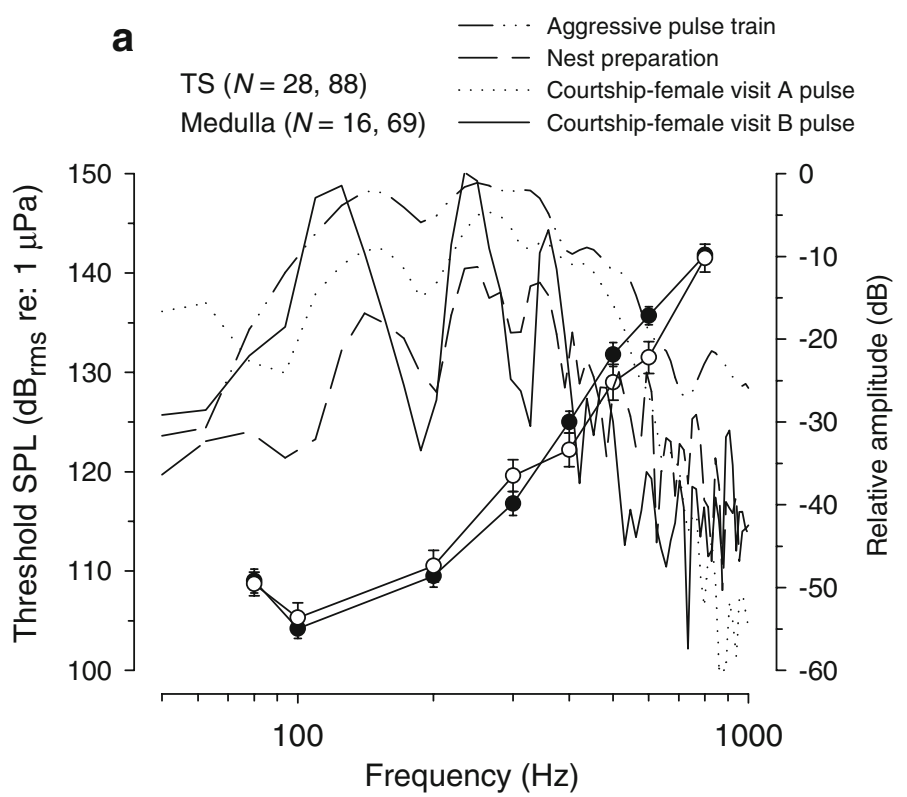

b

Courtship-female visit

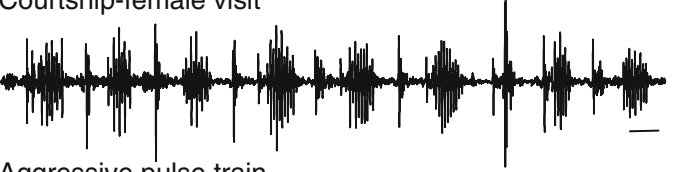

Aggressive pulse train

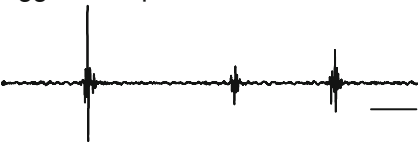

Courtship A pulses
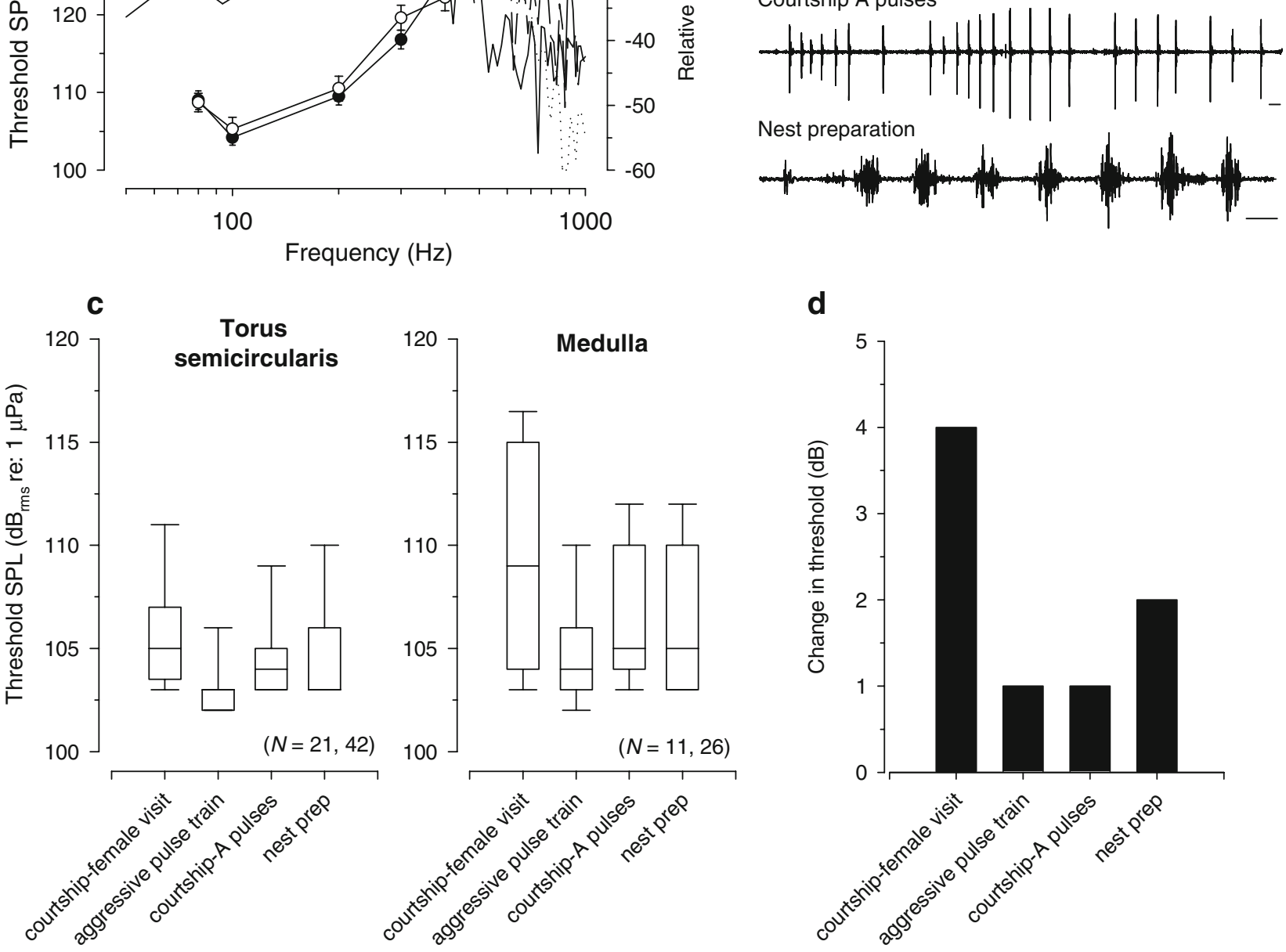

d

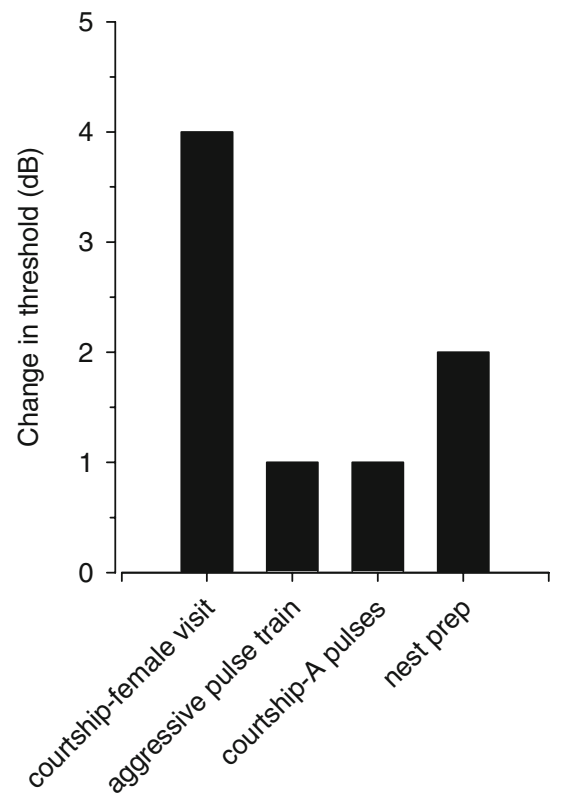

Fig. 6 Response of neurons in the midbrain torus semicircularis and medulla in response to sinusoid tone bursts and stimulus thresholds to playbacks of four natural conspecific sounds of different behavioral contexts. a Comparison of audiograms of neurons in the midbrain torus semicircularis $(T S)$ and medulla in response to tone burst stimuli and frequency spectra of the conspecific sounds used as stimuli. Audiogram data are plotted as the mean \pm SE for the TS (closed circles) and the medulla (open circles), and are referenced to the left $y$-axis. Power spectra (512 point FFT) of representative pulses from the four natural sounds used as playbacks are plotted as relative amplitude in $\mathrm{dB}$ (right $y$-axis) to illustrate the match between frequency content of natural sounds and the low-frequency tuning of

that of tones at $100 \mathrm{~Hz}$, but lower than those of tone bursts at all other frequencies. Midbrain neurons were also more sensitive to conspecific sounds compared to hindbrain the auditory brain. $N$ number of animals, number of units. b Waveforms of the four natural conspecific sounds used as playback stimuli for neurophysiology recordings. Scale bars $100 \mathrm{~ms}$. c Thresholds for all four natural sound stimuli in the TS were 104-106 dB re: $1 \mu \mathrm{Pa}$, which is $\pm 2 \mathrm{~dB}$ of the mean threshold for tone bursts at $100 \mathrm{~Hz}$, but lower than thresholds for all other frequencies. Similarly, thresholds for all four natural sounds in the medulla were 105-110 dB re: $1 \mu \mathrm{Pa}$. Data are plotted as medians and quartiles with error bars. d Midbrain TS neurons were $1-4 \mathrm{~dB}$ more sensitive to all conspecific sounds compared to the medulla under these experimental conditions. Data are plotted as the change in median $\mathrm{dB}$ between TS and medulla for each sound type. $N$ number of animals, number of units

neurons. These data demonstrate that both frequency and temporal information from the pulsed natural sounds produced by the Hawaiian sergeant fish are represented in the 

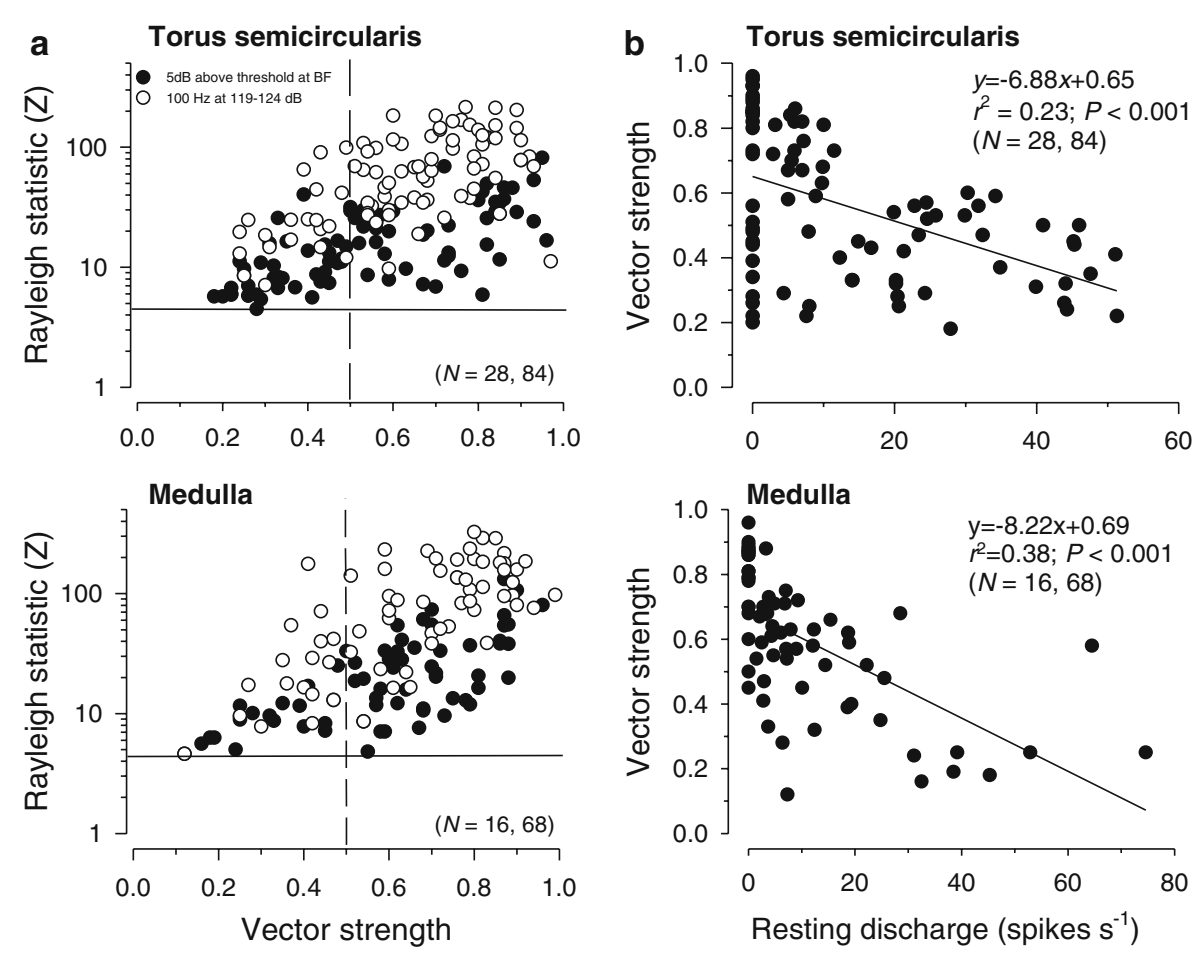

Fig. 7 Phase-locking ability of auditory neurons. a Scatter plot of Rayleigh statistic $(Z)$ versus vector strength of synchronization for auditory neurons in the torus semicircularis (TS) and medulla. Vector strength and $Z$ values were calculated both at $5 \mathrm{~dB}$ above threshold at each units' BF (closed circles) and at $100 \mathrm{~Hz}$ at 119-124 dB (open circles). The horizontal solid line indicates the critical value of the Rayleigh statistic (4.5) that divides the units into those with (above) and without (below) significant phase-locking. The vertical dashed line at vector strength $=0.5$ divides the units into those that show
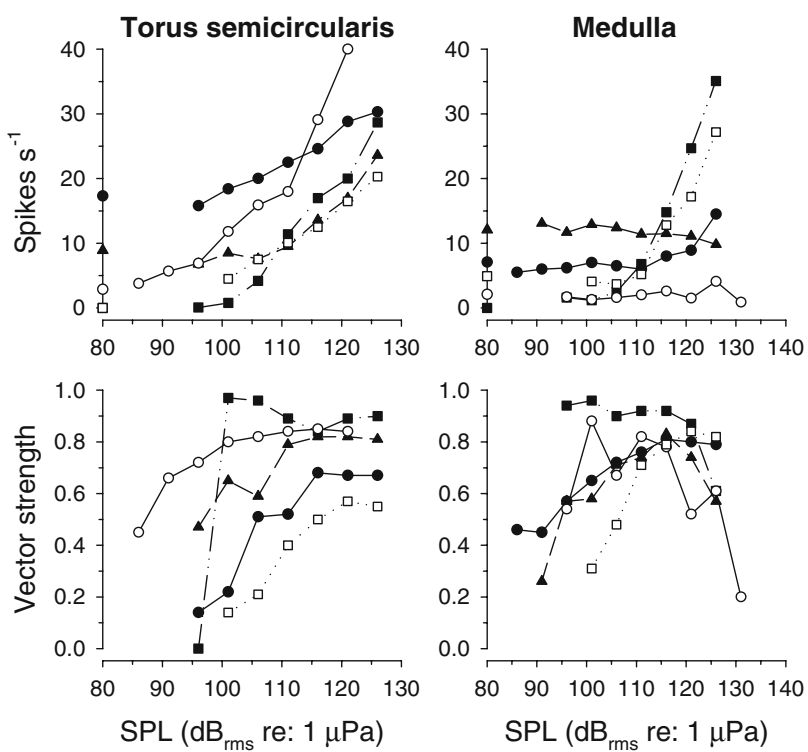

Fig. 8 Response-intensity curves at $100 \mathrm{~Hz}$ for five individual auditory neurons each from the torus semicircularis and medulla. Top graphs show rate-intensity curves and bottom graphs show synchronization-intensity curves. Resting discharge rates for each individual neuron are indicated on the $y$-axis of the top graphs

weak (left) and strong (right) phase-locking. $N$ number of animals, number of units. b Relationship between vector strength calculated at $5 \mathrm{~dB}$ above threshold at each units' $\mathrm{BF}$ and resting discharge rate for single auditory neurons. Auditory neurons with slower resting discharges have higher vector strength values (i.e. are more phaselocked) than those with higher resting discharges (linear regressions, $P<0.001)$ for both the TS and medulla. $N$ number of animals, number of units

auditory hindbrain and midbrain. Further studies are needed to determine which characteristics of natural sounds are important for auditory discrimination of different behaviors.

Resting discharge activity

The range of resting discharge activities for auditory neurons in the pomacentrid sergeant fish TS are similar to those reported for species in broad taxonomic groups. However, the mean discharge rate of 13.5 spikes s $^{-1}$ is approximately twice that reported for the salmonid trout (Schellart et al. 1987), cyprinid goldfish (Lu and Fay 1993) and mormyrid (Crawford 1993). In contrast, a lower resting

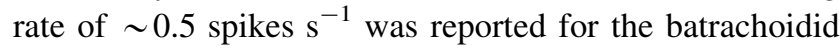
toadfish TS (Edds-Walton and Fay 2003). Further, the mean spike rate of 11 spikes $\mathrm{s}^{-1}$ for hindbrain units of the Hawaiian sergeant is similar to that of the toadfish DON (Edds-Walton and Fay 2008), but less than half that reported for the trout (Wubbels et al. 1993) and twice that for the goldfish (Page 1970). The cause or influence of the relatively high spontaneous discharge in the sergeant fish TS in auditory signal processing are still undetermined, but 


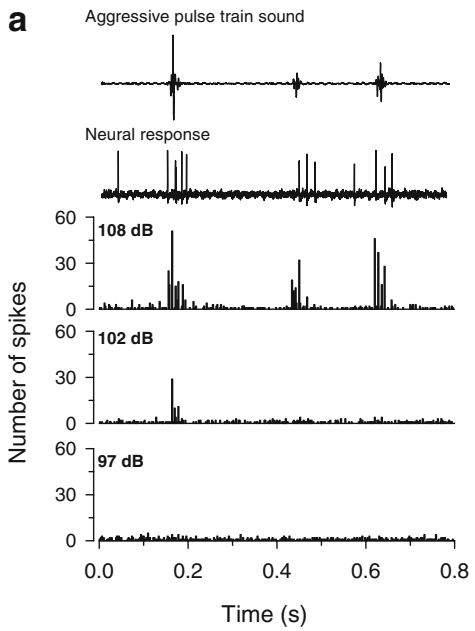

b
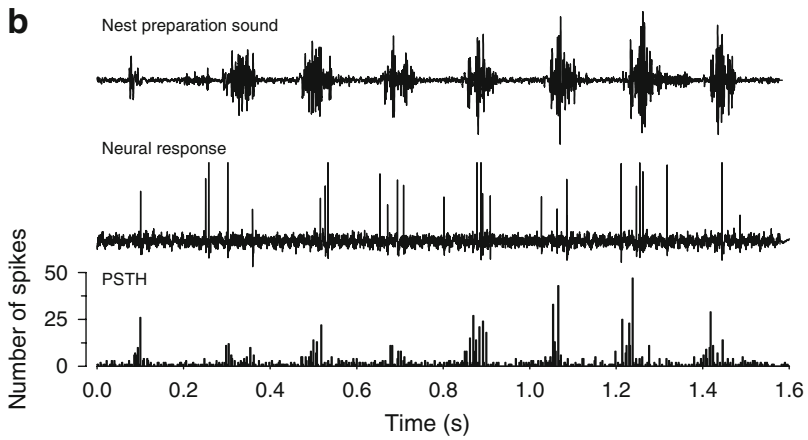

Fig. 9 Response of a representative torus semicircularis neuron to playbacks of natural conspecific sounds. a Response to an aggressive pulse train sound. Thresholds for natural sounds were determined as the lowest intensity to show a peri-stimulus time histogram (PSTH) with increased spike rates above background that were correlated in time with the stimulus waveform. The stimulus waveform and neural response are shown above the peri-stimulus time histograms. PSTHs are the response to 50 repetitions of the stimulus waveform at levels above $(108 \mathrm{~dB})$, at $(102 \mathrm{~dB})$, and below $(97 \mathrm{~dB})$ threshold. b Response to the nest preparation sound produced by a male while preparing a spawning substrate. Top shows the stimulus waveform, middle shows the neural response, and bottom shows the peri-stimulus time histogram of the response to 50 stimulus repetitions. Mean resting discharge of this unit was 5 spikes $\mathrm{s}^{-1}$

may be related to several factors such as species variations in peripheral auditory structures, convergence ratios, or differences in temperature, electrode bias, or recording site between studies. High spontaneous activity (up to 200 spikes s$^{-1}$ ) found in peripheral afferent neurons across a broad range of taxa may improve linear response to sinusoidal stimuli, while reduced resting activity in higher centers may improve feature processing for presence or absence of a stimulus (Feng and Schellart 1999).

Response to tone bursts: frequency response, phase-locking, threshold, and level encoding

Auditory neurons in the hindbrain and midbrain TS of the Hawaiian sergeant fish were most sensitive to low frequencies of $80-400 \mathrm{~Hz}$, which matches the relative frequency spectrum of sounds produced by this species (see Fig. 6 and Maruska et al. 2007). Previous studies suggest that auditory units at higher processing levels show progressively sharper tuning (i.e., TS units are more sharply tuned than primary afferents) (Page 1970; Lu and Fay 1993). It is difficult to comment on whether this hypothesis is supported in the Hawaiian sergeant fish until recordings from primary afferents are made, and additional stimulus frequencies between 100 and $300 \mathrm{~Hz}$ are tested (i.e., finer frequency resolution) in the region of best sensitivity. However, hindbrain neurons generally showed broader tuning curves compared to midbrain neurons. These data indicate presence of a filtering mechanism between hindbrain and midbrain levels that may function through inhibitory interactions to sharpen the frequency response at higher processing centers (Lu and Fay 1996; Feng and Schellart 1999). Inhibitory response areas adjacent to the neuron's excitatory area are often observed in two-tone interaction experiments in the fish TS, but not in earlier processing regions (Lu and Fay 1996; Feng and Schellart 1999). Sharpened midbrain tuning to stimuli around $100 \mathrm{~Hz}$ supports an importance of this low-frequency spectral information, possibly to facilitate acoustic communication or predator and prey detection. A similar situation exists in the toadfish brain where neurons from the midbrain TS had a lower mean BF than neurons in the DON of the hindbrain, but both were well-suited to detect the seasonal range of fundamental frequencies present in the natural 'boatwhistle' sounds produced during the breeding period (Fay and Edds-Walton 2000). In addition, while there was no difference in threshold between midbrain and hindbrain neurons to tone stimuli in the damselfish, midbrain neurons were more sensitive to complex conspecific sounds, which highlights the relevance and importance of testing complex natural sounds in neurophysiological studies of fish hearing.

Frequency information in fishes is preserved by phase-locking (i.e., synchronization of neural spikes to the stimulus cycle) (see Feng and Schellart 1999). Strong phaselocking to the stimulus is common in peripheral auditory fibers in fishes (Fay 1978a; Moeng and Popper 1984; Sisneros and Bass 2003), but often reduced at hindbrain, midbrain, and forebrain processing centers (Page 1970; Lu and Fay 1993, 1995; Bodnar and Bass 1997, Edds-Walton and Fay 2003). In the goldfish, about $50 \%$ of medullary units are phase-locked (Page 1970), while the trout shows about $95 \%$ (Wubbels et al. 1993), and most DON cells in the toadfish showed good phase-locking (Edds-Walton and Fay 2008). Similarly, all of the auditory neurons recorded in the Hawaiian sergeant fish medulla were phase-locked to tone stimuli from 80 to $800 \mathrm{~Hz}$. Phase-locking is ubiquitous in low-frequency afferents $(\lesssim 4 \mathrm{kHz})$ across all 
Fig. 10 Response of a representative medullary neuron to playbacks of natural conspecific sounds. a Response to the courtship-female visit sound. b Response to the courtship A pulses sound. Top trace in each panel shows the stimulus waveform, middle trace shows the neural response, and bottom trace shows the peri-stimulus time histogram of the response to 10 stimulus repetitions. Inset in a at top shows an expanded view of the neural response to a single $\mathrm{A}$ pulse followed by a B pulse of the courtship stimulus waveform (region outlined in rectangle). Mean resting discharge of this unit was 2.9 spikes s $^{-1}$

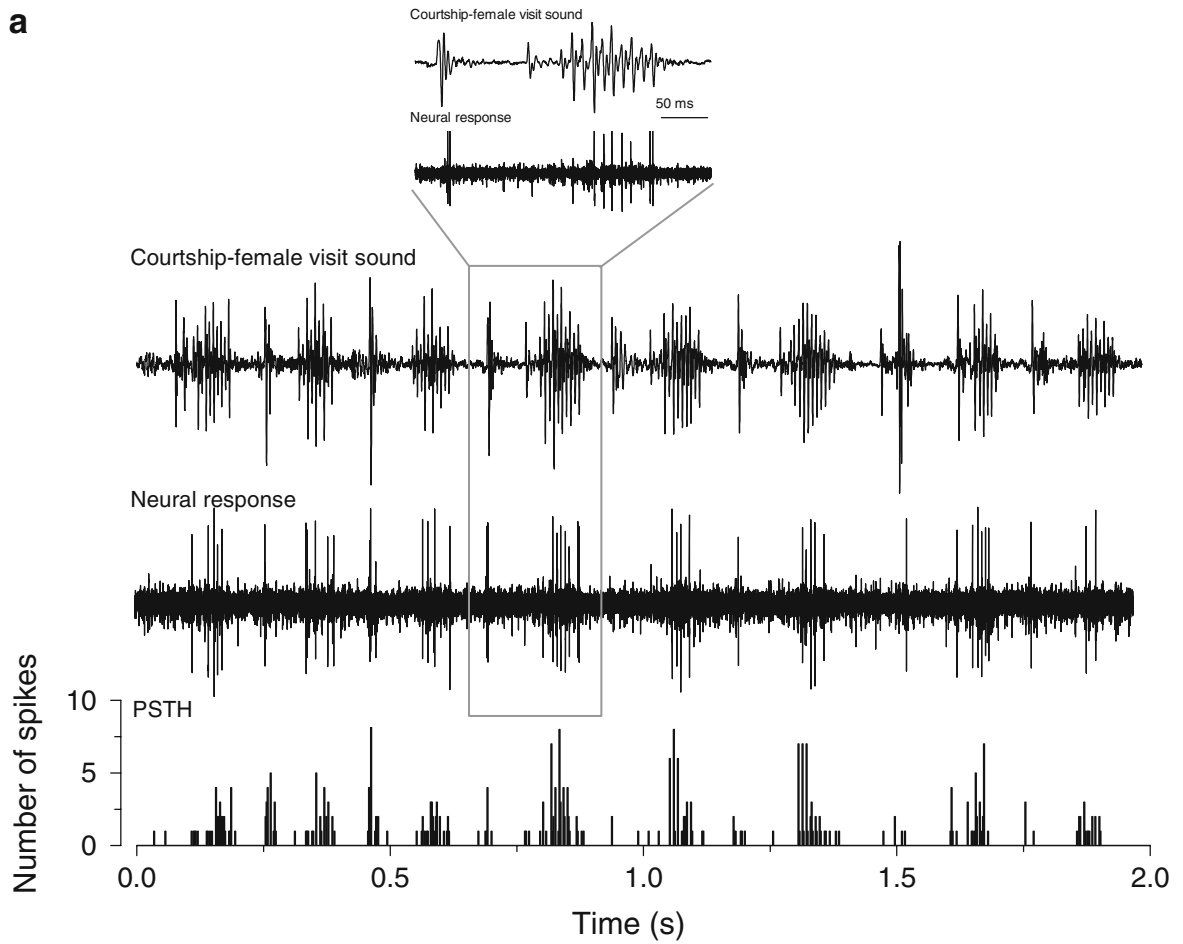

b
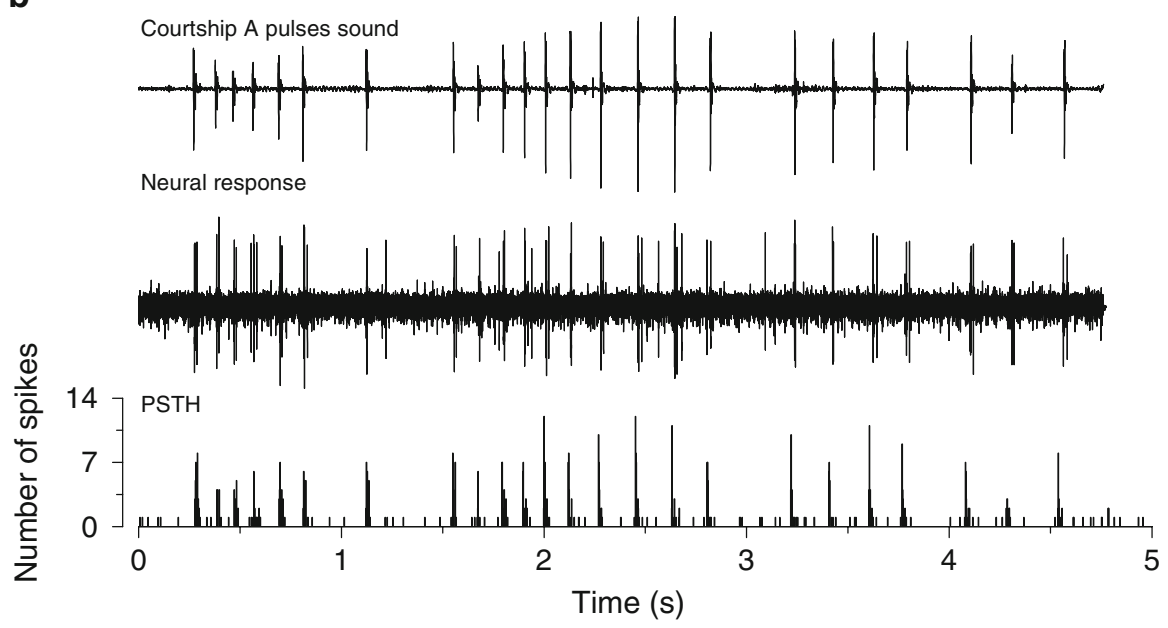

vertebrate auditory systems, enhances pitch perception to improve signal-to-noise ratio, and may be an ancestral characteristic of the neural code for hearing (Popper and Fay 1999).

Silent units showed the highest degree of phase-locking in the sergeant fish midbrain and hindbrain which is similar to that seen for directionally sensitive units in other fishes (Wubbels and Schellart 1997; Feng and Schellart 1999). The relatively high proportion of phase-locked units in the midbrain of the Hawaiian sergeant fish differs from other studies that show TS units with little to no phase-locking ability (Page 1970; Edds-Walton and Fay 2003). Lu and Fay (1993) showed that more than 50\% of goldfish TS neurons were synchronized, and $15 \%$ of these were strongly phase-locked. However, they also note that all of these strong phase-locked units were recorded with glass electrodes but could not be isolated with low-impedance indium electrodes. Strong phase-locked units $(\sim 10 \%$ of units) were also recorded in the midbrain of mormyrids (Crawford 1993). Recordings from the TS of the toadfish showed only a subset of phase-locked neurons, which were suggested to be components of the directional auditory circuit, while units that did not phase-lock were less directionally sensitive (Edds-Walton and Fay 2003). Similarly, a greater proportion (75\%) of direction-sensitive units in the TS of the trout showed synchronization compared to a smaller proportion (23\%) of non-directionally sensitive neurons (Wubbels and Schellart 1997). Thus, 
strong phase-locked units exist in the auditory midbrain of fishes and their frequency of occurrence may in part depend on position within the TS, directional selectivity, or may be species specific. Alternatively, differences among studies may reflect methodological variations such as electrode type or criteria used to define phase-locking. The high percentage of phase-locked neurons in the damselfish brain may also indicate greater frequency selectivity, although it is possible that some of the midbrain units recorded in our study were ascending medullary axons as suggested by Schellart et al. (1987).

Mean thresholds of single auditory neurons to tone burst stimuli were $\sim 105 \mathrm{~dB}_{\text {rms }}$ re: $1 \mu \mathrm{Pa}$ at the $\mathrm{BF}$ of $100 \mathrm{~Hz}$. However, thresholds of individual auditory neurons varied widely with some neurons $10-30 \mathrm{~dB}$ more sensitive than others at a given frequency. Further, some neurons only responded to low frequencies $(80-300 \mathrm{~Hz})$, but were insensitive to higher frequencies even at high stimulus intensities (140-150 dB). These differences in sensitivity may be due in part to differential inputs from the three otolithic endorgans with hair-cell orientations that deviate from the main vertical dorso-ventral axis of particle velocity stimulation used in this study.

Rate-intensity and synchronization-intensity curves for individual auditory units at $100 \mathrm{~Hz}$ in the Hawaiian sergeant fish varied in both slope and dynamic range. In many TS units, synchronization saturated at relatively lowintensity levels, while spike rates continued to increase with increasing sound levels. In these neurons, spike rate would better encode sound level compared to synchronization. In contrast, many neurons in the hindbrain showed that synchronization was more important in level encoding compared to spike rates. These data indicate there are subpopulations of neurons in both the midbrain and hindbrain that can provide information about stimulus level via different physiological mechanisms, but the mechanism may be frequency- and sound-intensity dependent. Similar variations in response-level curves among individual neurons are seen in the auditory system of the goldfish, midshipman, and toadfish (Fay 1978b; Fay 1985; McKibben and Bass 1999; Edds-Walton and Fay 2008). Sound level encoding is likely important for distance detection in the Hawaiian sergeant and other fishes, but further studies are needed to test this hypothesis.

Response to complex conspecific sounds

To our knowledge, this is the first study to use playbacks of natural complex conspecific sounds as stimuli to examine single neuron auditory encoding in the fish brain. A previous study used auditory evoked potential (AEP) recordings to show that temporal patterns, amplitude fluctuations, and frequency information of natural acoustic stimuli are represented in the slow wave responses of the fish auditory system (Wysocki and Ladich 2003). Our study demonstrates that this same type of information is distinguishable at the level of single neurons in the auditory hindbrain and midbrain. Use of natural sound stimuli to study fish hearing ability is important because the frequency bandwidth may be a more important indication of frequency tuning in fishes and other vertebrates (Fay 1992). Further, damselfish sounds are pulsed, and the temporal pattern of pulse delivery is important for communication, including species and individual identity in both damselfishes and other species such as sunfishes and cod (Gerald 1971; Hawkins and Rasmussen 1978; Myrberg et al. 1978; Spanier 1979; Zelick et al. 1999). Auditory neurons in the TS of the mormyrid fish Pollimyrus adspersus are selectively activated by temporal features of complex sounds such as inter-click intervals (Crawford 1997), neurons in the toadfish TS show interpulse interval selectivity (Fay and Edds-Walton 2002), and the midbrain neurons of the midshipman provide a combinatorial code of both the difference in frequency from overlapping calls of neighboring males and the spectral composition of individual calls (Bodnar and Bass 2001). Studies on sound production and hearing ability across vertebrate and invertebrate taxa stress the importance of temporal patterns in acoustic communication (Myrberg et al. 1978), and the auditory midbrain is well-suited to encode the temporal structure of natural vocalizations across vertebrates (Bass et al. 2005; Rees and Langner 2005). The representation of temporal patterns of conspecific sounds in the Hawaiian sergeant brain indicates it provides important information for integration with other sensory inputs and motor outputs to coordinate appropriate behavioral responses. However, due to the complicated nature of particle motion and pressure levels of complex sounds in small tanks, neural recordings in a free-field environment are needed to validate the responses reported here.

The Hawaiian sergeant fish produces several different types of pulsed sounds during territorial and reproductive behaviors, and the greatest energy for all sound types is in the range of $<80-400 \mathrm{~Hz}$ (Maruska et al. 2007). This lowfrequency spectral content is consistent with the best frequency sensitivity of neurons in the auditory hindbrain and midbrain. For example, the courtship-female visit sound is composed of two different pulse types, A and B. The A pulse is short and relatively broadband, while the B pulse is longer and generally has a pulse repetition rate of $\sim 125 \mathrm{~Hz}$ with multiple harmonic-like intervals up to $\sim 1 \mathrm{kHz}$ (Maruska et al. 2007). This 'grunt-like' sound is produced only when a male leads a female back to his nest and the pair is in close proximity to each other. The average BF of single auditory neurons was $127 \mathrm{~Hz}$ in the TS and $134 \mathrm{~Hz}$ in the hindbrain, which corresponds to 
the pulse repetition rate range $(120-130 \mathrm{~Hz})$ of the $\mathrm{B}$ pulse of the courtship-female visit sound. The most common BFs of midbrain neurons also correspond to the pulse repetition rate of natural sounds in toadfish (Bass et al. 2001; EddsWalton and Fay 2003), midshipman (Bodnar and Bass 1997), and mormyrids (Crawford 1993). Midbrain auditory neurons also showed a greater sensitivity to both courtshiprelated sound types compared to hindbrain neurons, which can also translate into enhanced detection distance. Thus, the auditory midbrain is well-adapted to encode these particular types of natural sounds, which may be significant for integration with other cues detected by the visual and lateral line systems during reproductive behaviors. Future studies are needed to determine the behavioral importance of the different spectral and temporal sound characteristics in the Hawaiian sergeant fish.

Acknowledgments We thank Geoff Horseman of Cambridge Electronics Design for help with Spike 2 scripts, two anonymous reviewers for helpful comments on the manuscript, and Sigma-Xi Grants-in-Aid of Research, the Hawaii Chapter of the ARCS Foundation, Lord Scholarship Fund, and a National Science Foundation Doctoral Dissertation Improvement Grant (DDIG IBN 04-08197) for partial funding. All experimental procedures followed guidelines for the care and use of animals and were approved by the University of Hawai'i Institutional Animal Care and Use Committee. This is contribution number 1359 from the Hawai'i Institute of Marine Biology.

\section{References}

Amorim MCP (2006) Diversity of sound production. In: Ladich F, Collin SP, Moller P, Kapoor BG (eds) Communication in fishes. Science Publishers, Enfield, NH, pp 71-105

Bass AH, McKibben JR (2003) Neural mechanisms and behaviors for acoustic communication in teleost fish. Prog Neurobiol 69:1-26

Bass AH, Bodnar DA, Marchaterre MA (2001) Acoustic nuclei in the medulla and midbrain of the vocalizing Gulf toadfish (Opsanus beta). Brain Behav Evol 57:63-79

Bass AH, Rose GJ, Pritz MB (2005) Auditory midbrain of fish, amphibians, and reptiles: model systems for understanding auditory function. In: Winer JA, Schreiner CE (eds) The inferior colliculus. Springer, New York, pp 459-492

Batschelet E (1981) Circular statistics in biology. Academic, New York

Bodnar DA, Bass AH (1997) Temporal coding of concurrent acoustic signals in auditory midbrain. J Neurosci 17:7553-7564

Bodnar DA, Bass AH (1999) Midbrain combinatorial code for temporal and spectral information in concurrent acoustic signals. J Neurophysiol 81:552-563

Bodnar DA, Bass AH (2001) Coding of concurrent vocal signals by the auditory midbrain: effects of stimulus level and depth of modulation. J Acoust Soc Am 109:809-825

Crawford JD (1993) Central auditory neurophysiology of a soundproducing fish: the mesencephalon of Pollimyrus isidori (Mormyridae). J Comp Physiol A 172:139-152

Crawford JD (1997) Feature-detecting auditory neurons in the brain of a sound-producing fish. J Comp Physiol A 180:439-450

Edds-Walton PL, Fay RR (1998) Directional auditory responses in the descending octaval nucleus of the toadfish (Opsanus tau). Biol Bull 195:191-192
Edds-Walton PL, Fay RR (2003) Directional selectivity and frequency tuning of midbrain cells in the oyster toadfish, Opsanus tau. J Comp Physiol A 189:527-543

Edds-Walton PL, Fay RR (2005) Sharpening of directional responses along the auditory pathway of the oyster toadfish, Opsanus tau. J Comp Physiol A 191:1079-1086

Edds-Walton PL, Fay RR (2008) Directional and frequency response characteristics in the descending octaval nucleus of the toadfish (Opsanus tau). J Comp Physiol A 194:1013-1029

Enger PS (1967) Hearing in herring. Comp Biochem Physiol 22:527538

Fay RR (1978a) Phase-locking in goldfish saccular nerve fibers accounts for frequency discrimination capacities. Nature 275:320-322

Fay RR (1978b) Coding of information in single auditory-nerve fibers of the goldfish. J Acoust Soc Am 63:136-146

Fay RR (1982) Neural mechanisms of an auditory temporal discrimination by the goldfish. J Comp Physiol A 147:201-216

Fay RR (1985) Sound intensity processing by the goldfish. J Acoust Soc Am 78:1296-1309

Fay RR (1990) Suppression and excitation in auditory nerve fibers of the goldfish, Carassius auratus. Hear Res 48:93-110

Fay RR (1992) Structure and function in sound discrimination among vertebrates. In: Webster DB, Fay RR, Popper AN (eds) The evolutionary biology of hearing. Springer-Verlag, New York, pp 229-263

Fay RR (1994) The sense of hearing in fishes: psychophysics and neurophysiology. Sens Syst 8:262-268

Fay RR, Edds-Walton PL (2000) Frequency response of auditory brainstem units in toadfish (Opsanus tau). Biol Bull 199:173-174

Fay RR, Edds-Walton PL (2002) Preliminary evidence for interpulse interval selectivity of cells in the torus semicircularis of the oyster toadfish (Opsanus tau). Biol Bull 203:195-196

Fay RR, Hillery CM, Bolan K (1982) Representation of sound pressure and particle motion information in the midbrain of the goldfish. Comp Biochem Physiol A 7:181-191

Feng AS, Schellart NAM (1999) Central auditory processing in fish and amphibians. In: Fay RR, Popper AN (eds) Comparative hearing: fish and amphibians. Springer-Verlag, New York, pp 218-268

Gerald JW (1971) Sound production in six species of sunfish (Centrarchidae). Evolution 25:75-87

Goldberg JM, Brown PB (1969) Response of binaural neurons of dog superior olivary complex to dichotic tonal stimuli: some physiological mechanisms of sound localization. J Neurophysiol 32:613-636

Hawkins AD, Rasmussen KJ (1978) The calls of Gadoid fish. J Mar Biol Assoc UK 58:891-911

Horodysky AZ, Brill RW, Fine ML, Musick JA, Latour RJ (2008) Acoustic pressure and particle motion thresholds in six sciaenid fishes. J Exp Biol 211:1504-1511

Javel E, Mott JB (1988) Physiological and psychophysical correlates of temporal processes in hearing. Hear Res 34:275-294

Kozloski J, Crawford JD (2000) Transformations of an auditory temporal code in the medulla of a sound-producing fish. J Neurosci 20:2400-2408

Ladich F, Myrberg AA (2006) Agonistic behavior and acoustic communication. In: Ladich F, Collin SP, Moller P, Kapoor BG (eds) Communication in fishes. Science Publishers, Enfield, NH, pp 121-148

Lobel PS, Mann D (1995) Spawning sounds of the damselfish, Dascyllus albisella (Pomacentridae), and relationship to male size. Bioacoustics 6:187-198

Lu Z, Fay RR (1993) Acoustic response properties of single units in the torus semicircularis of the goldfish, Carassius auratus. J Comp Physiol A 173:33-48 
Lu Z, Fay RR (1995) Acoustic response properties of single neurons in the central posterior nucleus of the thalamus of the goldfish, Carassius auratus. J Comp Physiol A 176:747-760

Lu Z, Fay RR (1996) Two-tone interaction in primary afferents and midbrain neurons of the goldfish, Carassius auratus. Audit Neurosci 2:257-273

Ma WLD, Fay RR (2002) Neural representations of the axis of acoustic particle motion in nucleus centralis of the torus semicircularis of the goldfish, Carassius auratus. J Comp Physiol A 188:301-318

Maruska KP, Tricas TC (2009) Central projections of octavolateralis nerves in the brain of a soniferous damselfish (Abudefduf abdominalis). J Comp Neurol 512:628-650

Maruska KP, Boyle KS, Dewan LR, Tricas TC (2007) Sound production and spectral hearing sensitivity in the Hawaiian sergeant damselfish, Abudefduf abdominalis. J Exp Biol 21:3990-4005

McCormick CA (1992) Evolution of central auditory pathways in anamniotes. In: Webster DB, Fay RR, Popper AN (eds) The evolutionary biology of hearing. Springer-Verlag, New York, pp 323-350

McCormick CA (1999) Anatomy of the central auditory pathways of fish and amphibians. In: Fay RR, Popper AN (eds) Comparative hearing: fish and amphibians. Springer, New York, pp 155-217

McKibben JR, Bass AH (1999) Peripheral encoding of behaviorally relevant acoustic signals in a vocal fish: single tones. J Comp Physiol A 184:563-576

Moeng RS, Popper AN (1984) Auditory response of saccular neurons of the catfish, Ictalurus punctatus. J Comp Physiol A 155:615624

Myrberg AA, Lugli M (2006) Reproductive behavior and acoustical interactions. In: Ladich F, Collin SP, Moller P, Kapoor BG (eds) Communication in fishes. Science Publishers, Enfield, NH, pp 149-176

Myrberg AA, Spanier E, Ha S (1978) Temporal patterning in acoustical communication. In: Reese ES, Lighter FJ (eds) Contrasts in behavior. Wiley, New York, pp 137-179

Myrberg AA, Ha SJ, Shamblott MJ (1993) The sounds of bicolor damselfish (Pomacentrus partitus): predictors of body size and a spectral basis for individual recognition and assessment. J Acoust Soc Am 94:3067-3070

Nederstigt LJA, Schellart NAM (1986) Acousticolateral processing in the torus semicircularis of the trout Salmo gairdneri. Pflügers Arch 406:151-157

O'Marra SK, McCormick CA (1999) Organization and connections of the dorsal descending nucleus and other presumed acoustic areas in the brainstem of the teleost fish, Astronotus ocellatus. Hear Res 129:7-19

Page CH (1970) Electrophysiological study of auditory responses in the goldfish brain. J Neurophysiol 33:116-128

Parvulescu A (1967) The acoustics of small tanks. In: Tavolga WN (ed) Marine bioacoustics. Pergamon Press, Oxford, pp 7-14

Plassmann W (1985) Coding of amplitude-modulated tones in the central auditory system of catfish. Hear Res 17:209-217
Popper AN, Fay RR (1999) The auditory periphery in fishes. In: Fay RR, Popper AN (eds) Comparative hearing: fish and amphibians. Springer-Verlag, New York, pp 43-100

Rees A, Langner G (2005) Temporal coding in the auditory midbrain. In: Winer JA, Schreiner CE (eds) The inferior colliculus. Springer, New York, pp 346-376

Sawa M (1976) Auditory responses from single neurons of the medulla oblongata in the goldfish. Bull Jap Soc Sci Fish 42:141152

Schellart NAM (1983) Acousticolateral and visual processing and their interaction in the torus semicircularis of the trout, Salmo gairdneri. Neurosci Lett 42:39-44

Schellart NAM, Kamermans M, Nederstigt LJA (1987) An electrophysiological study of the topographical organization of the multisensory torus semicircularis of the rainbow trout. Comp Biochem Physiol 406:151-157

Sisneros JA (2007) Saccular potentials of the vocal plainfin midshipman fish, Porichthys notatus. J Comp Physiol A 193:413-424

Sisneros JA, Bass AH (2003) Seasonal plasticity of peripheral auditory frequency sensitivity. J Neurosci 23:1049-1058

Spanier E (1979) Aspects of species recognition by sound in four species of damselfish, genus Eupomacentrus (Pisces: Pomacentridae). Z Tierpsychol 54:301-316

Striedter G (1991) Auditory, electrosensory, and mechanosensory lateral line pathways through the forebrain in channel catfishes. J Comp Neurol 312:311-331

Suzuki A, Kozloski J, Crawford JD (2002) Temporal encoding for auditory computation: physiology of primary afferent neurons in sound-producing fish. J Neurosci 222:6290-6301

Tomchik SM, Lu Z (2005) Octavolateral projections and organization in the medulla of a teleost fish, the sleeper goby (Dormitator latifrons). J Comp Neurol 481:96-117

Weeg M, Fay RR, Bass AH (2002) Directionality and frequency tuning of primary saccular afferents of a vocal fish, the plainfin midshipman (Porichthys notatus). J Comp Physiol A 188:631641

Wubbels RJ, Schellart NAM (1997) Neural encoding of sound direction in the auditory midbrain of the rainbow trout. J Neurophys 77:3060-3074

Wubbels RJ, Kroese ABA, Schellart NAM (1993) Response properties of lateral line and auditory units in the medulla oblongata of the rainbow trout (Oncorhynchus mykiss). J Exp Biol 179:77-92

Wubbels RJ, Schellart NAM, Goossens JHLM (1995) Mapping of sound direction in the trout lower midbrain. Neurosci Lett 199:179-182

Wysocki LE, Ladich F (2003) The representation of con-specific sounds in the auditory brainstem of teleost fishes. J Exp Biol 206:2229-2240

Zelick R, Mann DA, Popper AN (1999) Acoustic communication in fishes and frogs. In: Fay RR, Popper AN (eds) Comparative hearing: fish and amphibians. Springer-Verlag, New York, pp 363-411 